Supporting Information of synthesis, structures, NMR and EPR spectroscopy and computations

\title{
Synthesis of a heterobimetallic arsenic triple-decker complex and its fragmentation chemistry
}

Martin Piesch ${ }^{[a]}$ and Manfred Scheer ${ }^{*[a]}$

Department of Inorganic Chemistry, Universität Regensburg, 93040 Regensburg, Germany

To whom correspondence should be addressed. Email: Manfred.Scheer@ur.de

\section{Table of Contents}

1. Synthetic procedures and experimental details........................................................ 2

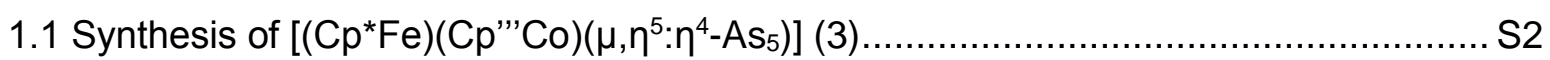

1.2 Synthesis of $\left[\left(\mathrm{Cp}{ }^{*} \mathrm{Fe}\right)\left(\mathrm{Cp} p^{\prime \prime} \mathrm{Co}\right)\left(\mu, \eta^{3}: \eta^{3}-\mathrm{As}_{3}\right)\right](4)$ and $\left[\left(\mathrm{Cp}{ }^{*} \mathrm{Fe}\right)_{2}\left(\mathrm{Cp} \mathrm{p}^{\prime \prime} \mathrm{Co}\right)_{2}\left(\mu_{4}, \eta^{4}: \eta^{4}: \eta^{4}: \eta^{3}-\right.\right.$

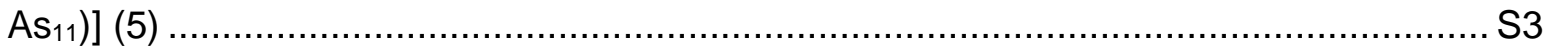

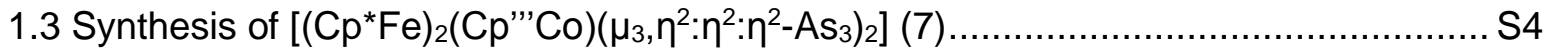

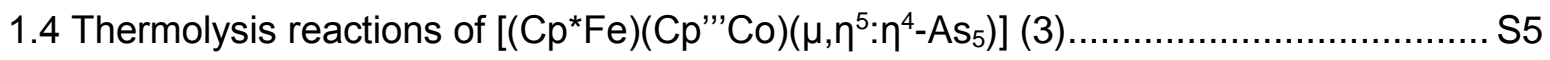

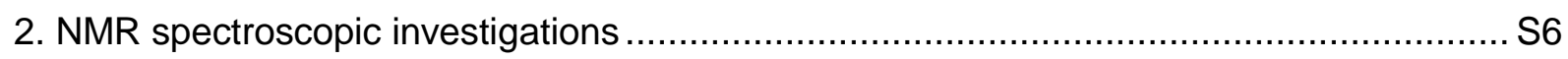

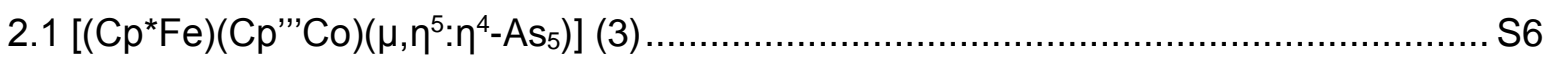

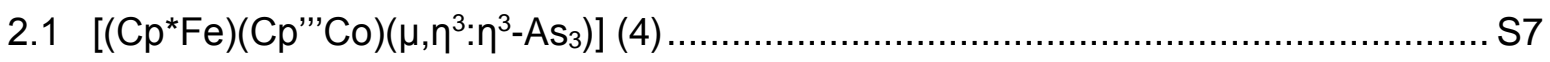

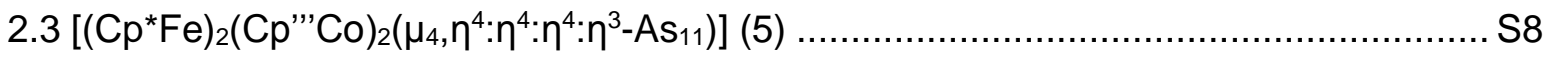

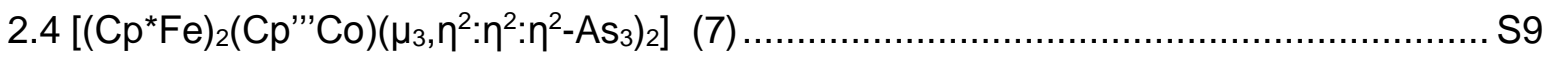

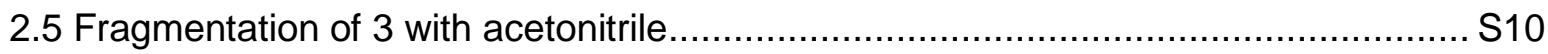

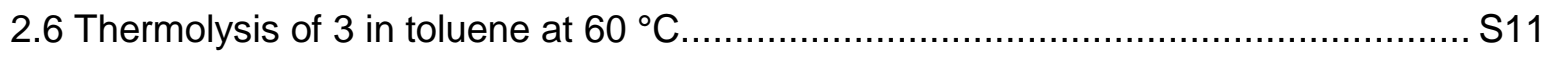

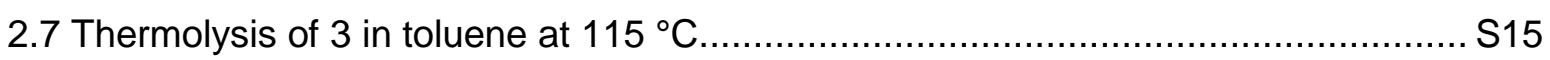

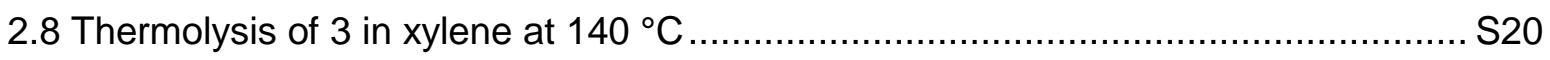

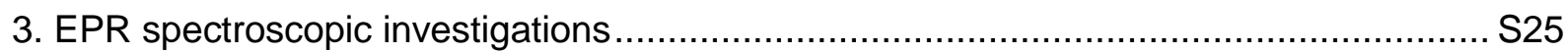

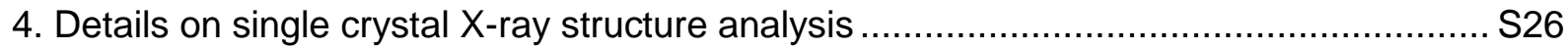

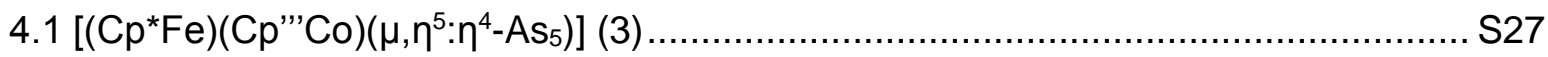

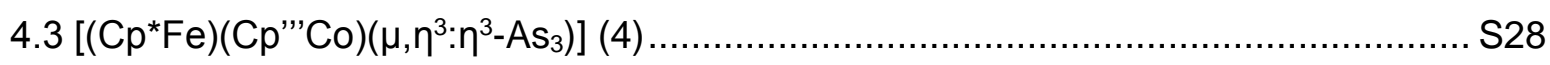

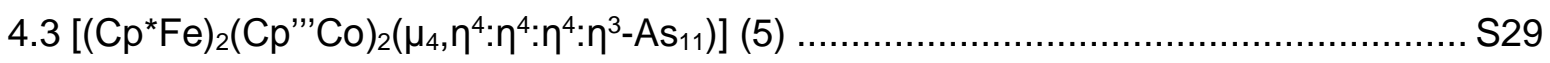

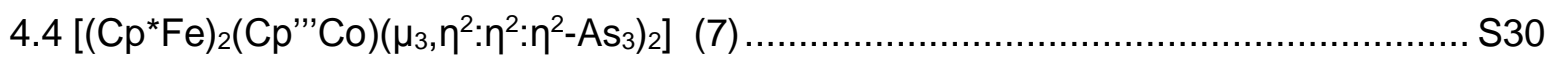

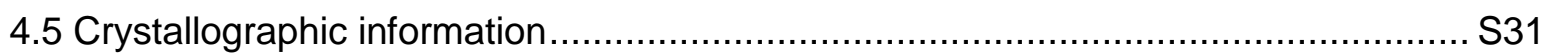

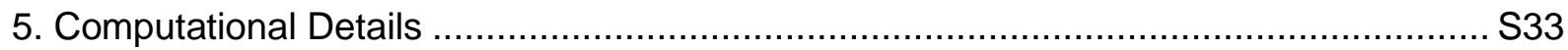

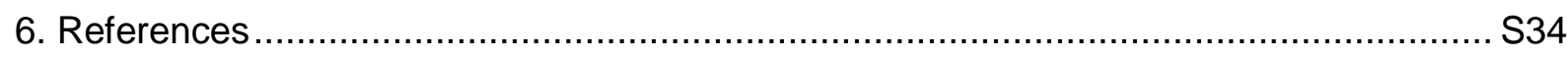




\section{Synthetic procedures and experimental details}

Synthetic Procedures: All manipulations were performed under an atmosphere of dry argon using standard glove-box and Schlenk techniques. All solvents were degassed and purified by standard procedures. The compounds $\left[(\mathrm{Cp} " ' \mathrm{Co})_{2}\left(\mu, \eta^{4}: \eta^{4}-\mathrm{C}_{7} \mathrm{H}_{8}\right)\right](\mathbf{2})^{[1]},\left[\mathrm{Cp}{ }^{*} \mathrm{Fe}\left(\eta^{5}-\mathrm{As}_{5}\right)\right](\mathbf{1 b})^{[2]}$ and $\left[(\mathrm{Cp} \text { "' } \mathrm{CoCl})_{2}\right]^{[3]}$ were prepared according to literature procedures.

The NMR spectra were recorded with a Bruker Avance 400 spectrometer $\left({ }^{1} \mathrm{H}: 400.13 \mathrm{MHz}\right.$, $\left.{ }^{31} \mathrm{P}: 161.976 \mathrm{MHz}\right)$. The chemical shifts are given in ppm referenced to external $\mathrm{SiMe}_{4}\left({ }^{1} \mathrm{H}\right)$ and $\mathrm{H}_{3} \mathrm{PO}_{4}\left({ }^{31} \mathrm{P}\right)$. Elemental analyses were determined with an Elementar Vario EL III apparatus. All mass spectra were recorded with a Finnigan MAT 95 mass spectrometer (LIFDI-MS). The X-Band EPR measurements were carried out with a MiniScope MS400 device with a frequency of $9.44 \mathrm{GHz}$ and a rectangular resonator TE102 of the company Magnettech $\mathrm{GmbH}$.

\subsection{Synthesis of $\left[\left(\mathrm{Cp}^{*} \mathrm{Fe}\right)\left(\mathrm{Cp} p^{\prime \prime} \mathrm{Co}\right)\left(\mu, \eta^{5}: \eta^{4}-\mathrm{As} 5\right)\right](3)$}

A solution of $\left[(\mathrm{Cp} " \mathrm{Co})_{2}\left(\mu, \eta^{4}: \eta^{4}-\mathrm{C}_{7} \mathrm{H}_{8}\right)\right](2)(598 \mathrm{mg}, 0.884 \mathrm{mmol}, 1 \mathrm{eq})$ in $50 \mathrm{~mL}$ pentane was added dropwise to a stirred solution of $\left[\mathrm{Cp}^{*} \mathrm{Fe}\left(\mathrm{n}^{5}-\mathrm{As}_{5}\right)\right](\mathbf{1 b})(1.00 \mathrm{~g}, 1.768 \mathrm{mmol}, 2 \mathrm{eq})$ in $200 \mathrm{~mL}$ pentane. The color changed to dark green after one hour. The ${ }^{1} \mathrm{H}$ NMR spectrum of the reaction mixture reveals the clean formation of $\mathbf{3}$ beside unused $\mathbf{1 b}$ in a ratio of 91:9. Further 2 (51 mg, $0.075 \mathrm{mmol}$ ) in pentane was added and stirred for another hour. The solvent was removed in vacuo. $\mathbf{3}$ can be obtained as a dark green solid. Very few crystals of $\mathbf{3}$ suitable for X-ray single crystal structure analysis can be obtained from a concentrated solution in $\mathrm{CH}_{2} \mathrm{Cl}_{2}$ layered with acetonitrile at $-30^{\circ} \mathrm{C}$ after a few days beside decomposition products (vide infra).

Yield: $1.373 \mathrm{~g}(91 \%)$.

${ }^{1} \mathrm{H}$ NMR $\left(\mathrm{C}_{6} \mathrm{D}_{6}, 293 \mathrm{~K}\right): \delta[\mathrm{ppm}]=3.67\left(\mathrm{~s}, 2 \mathrm{H}, \mathrm{C}_{5} \mathrm{H}_{2}{ }^{\mathrm{B}} \mathrm{Bu} u_{3}\right), 1.43\left(\mathrm{~s}, 18 \mathrm{H}, \mathrm{C}_{5} \mathrm{H}_{2}{ }^{t} B u_{3}\right), 1.40(\mathrm{~s}, 15 \mathrm{H}$, $\left.\mathrm{C}_{5} \mathrm{Me}_{5}\right), 1.33\left(\mathrm{~s}, 9 \mathrm{H}, \mathrm{C}_{5} \mathrm{H}_{2}{ }^{t} \mathrm{Bu}_{3}\right)$.

LIFDI-MS (toluene): $\mathrm{m} / \mathrm{z}=932.6\left(4 \%,[\mathrm{M}+\mathrm{As}]^{+}\right), 857.7\left(100 \%,[\mathrm{M}]^{+}\right), 782.8\left(4 \%,[\mathrm{M}-\mathrm{As}]^{+}\right)$, $707.9\left(15 \%,[\mathrm{M}-2 \mathrm{As}]^{+}\right)$.

EA: $\mathrm{C}_{27} \mathrm{H}_{44} \mathrm{CoFeAs}_{5}$ : calc [\%]: C: 37.79; $\mathrm{H}: 5.17$; found [\%]: C: $37.32 ; \mathrm{H}: 5.17$. 


\subsection{Synthesis of $\left[\left(\mathrm{Cp}^{*} \mathrm{Fe}\right)\left(\mathrm{Cp} \mathrm{p}^{\prime \prime} \mathrm{Co}\right)\left(\mu, \eta^{3}: \eta^{3}-\mathrm{As} 3\right)\right](4)$ and $\left[\left(\mathrm{Cp}{ }^{*} \mathrm{Fe}\right)_{2}\left(\mathrm{Cp} \mathrm{p}^{\prime \prime} \mathrm{Co}\right)_{2}\left(\mu_{4}, \eta^{4}: \eta^{4}: \eta^{4}: \eta^{3}-\mathrm{As} \mathrm{s}_{11}\right)\right](5)$}

$10 \mathrm{~mL}$ MeCN were added to a solution of $3(1.00 \mathrm{~g}, 1.166 \mathrm{mmol})$ in $50 \mathrm{~mL} \mathrm{CH}_{2} \mathrm{Cl}_{2}$ and stirred for three days. The color changed from dark green to brown green. The ${ }^{1} \mathrm{H}$ NMR spectrum reveals a mixture of 3 , $\left[\left(\mathrm{Cp}{ }^{*} \mathrm{Fe}\right)\left(\mathrm{Cp} \mathrm{p}^{\prime \prime} \mathrm{Co}\right)\left(\mu, \eta^{3}: \eta^{3}-\mathrm{As} s_{3}\right)\right] \quad$ (4) and $\left[\left(\mathrm{Cp}{ }^{*} \mathrm{Fe}\right)_{2}\left(\mathrm{Cp} p^{\prime \prime} \mathrm{Co}\right)_{2}\left(\mu_{4}, \eta^{4}: \eta^{4}: \eta^{4}: \eta^{3}-\mathrm{As}_{11}\right)\right](5)$. The solvent was removed in vacuo. The residue was dissolved in $\mathrm{CH}_{2} \mathrm{Cl}_{2}, \mathrm{SiO}_{2}$ added and dried in vacuo. The preabsorbed crude mixture was purified by column chromatography $\left(\mathrm{SiO}_{2}\right.$, pentane, $\left.25 \times 3 \mathrm{~cm}\right)$. Using pentane a dark green fraction can eluted containing a mixture of 3 and $\mathbf{4}$ in a ratio of 22:78 which cannot be separated further from each other (using alumina for column chromatography and using thin layer chromatography with silica and alumina, respectively were not successful). Using toluene, a strong dark brown fraction of $\mathbf{5}$ can be eluted. The solvent was removed in vacuo, the residue dissolved in $\mathrm{CH}_{2} \mathrm{Cl}_{2}$ and layered with $\mathrm{MeCN}$ at room temperature. After a few days 3 can be obtained as dark brown blocks. The supernatant was decanted off and the remaining crystals dried in vacuo. The mixture of $\mathbf{3}$ and $\mathbf{4}$ was dissolved in hexane and stored at $-30^{\circ} \mathrm{C}$. After a few days two kind of slightly different shaped crystals were obtained, which were separated under the microscope yielding a few $\mathrm{mg}$ on analytically pure 4.

Compound 4:

Yield: $10 \mathrm{mg}$

${ }^{1} \mathrm{H}$ NMR $\left(\mathrm{C}_{6} \mathrm{D}_{6}, 293 \mathrm{~K}\right): \delta[p p m]=5.31\left(\mathrm{~s}, 2 \mathrm{H}, \mathrm{C}_{5} \mathrm{H}_{2}{ }^{\mathrm{t} B \mathrm{Bu}_{3}}\right), 1.60\left(\mathrm{~s}, 15 \mathrm{H}, \mathrm{C}_{5} \mathrm{Me}_{5}\right), 1.30(\mathrm{~s}, 18 \mathrm{H}$, $\left.\mathrm{C}_{5} \mathrm{H}_{2}^{t} B u_{3}\right), 0.66\left(\mathrm{~s}, 9 \mathrm{H}, \mathrm{C}_{5} \mathrm{H}_{2}^{t} B u_{3}\right)$.

LIFDI-MS (toluene): $m / z=708.0\left(100 \%,[\mathrm{M}]^{+}\right)$.

EA: $\mathrm{C}_{27} \mathrm{H}_{44} \mathrm{CoFeAs}_{3}$ : calc [\%]: C: 45.79; $\mathrm{H}: 6.26$; found [\%]: C: 45.62; $\mathrm{H}: 6.05$.

Compound 5:

Yield : $366 \mathrm{mg}(0.204 \mathrm{mmol}, 44 \%$ related to 3 using the stoichiometry of 5 $\left[(\mathrm{Cp} * \mathrm{Fe})\left(\mathrm{Cp}\right.\right.$ "'Co $\left.\mathrm{As}_{5}\right] \rightarrow\left[\left(\mathrm{Cp}{ }^{*} \mathrm{Fe}\right)\left(\mathrm{Cp}{ }^{\prime \prime \prime} \mathrm{Co}\right) \mathrm{As}_{3}+2\left[\left(\mathrm{Cp}{ }^{*} \mathrm{Fe}\right)_{2}\left(\mathrm{Cp}{ }^{\prime \prime \prime C o}\right)_{2} \mathrm{As}_{11}\right]\right)$.

${ }^{1} \mathrm{H}$ NMR $\left(\mathrm{C}_{6} \mathrm{D}_{6}, 293 \mathrm{~K}\right): \delta[\mathrm{ppm}]=9.84\left(\mathrm{br}, 2 \mathrm{H}, \mathrm{C}_{5} \mathrm{H}_{2}{ }^{\mathrm{t} B u_{3}}\right), 4.27\left(\mathrm{~s}, 2 \mathrm{H}, \mathrm{C}_{5} \mathrm{H}_{2}{ }^{\mathrm{t} B u_{3}}\right), 2.36(\mathrm{br}, 36 \mathrm{H}$, $\left.\mathrm{C}_{5} \mathrm{H}_{2}{ }^{t} B u_{3}\right), 1.53\left(\mathrm{~s}, 9 \mathrm{H}, \mathrm{C}_{5} \mathrm{H}_{2}{ }^{t} B u_{3}\right),-0.51\left(\mathrm{br}, 9 \mathrm{H}, \mathrm{C}_{5} \mathrm{H}_{2}{ }^{t} B u_{3}\right),-1.14\left(\mathrm{br}, 15 \mathrm{H}, \mathrm{C}_{5} M e_{5}\right),-18.25(\mathrm{br}$, $\left.15 \mathrm{H}, \mathrm{C}_{5} \mathrm{Me}_{5}\right)$.

Evans-NMR $\left(\mathrm{C}_{6} \mathrm{D}_{6}, 293 \mathrm{~K}\right): \mu_{\text {eff }}=2.27 \mu_{\mathrm{B}}$ corresponding to 1.48 unpaired electrons.

LIFDI-MS (toluene): $\left.m / z=1224.9(20 \% \text {, [M-Cp*Fe-5As] }]^{+}\right), 1123.9\left(11 \%\right.$, [M-Cp'"Co-5As] $\left.{ }^{+}\right)$, 1007.7 (7\%, [M-Cp*Fe-Cp'”Co-4As] $\left.{ }^{+}\right), 932.8$ (70\%, [M-Cp*Fe-Cp"'Co-5As] $\left.{ }^{+}\right), 857.9$ (100\%, $\left.\left[\mathrm{M}-\mathrm{Cp}{ }^{*} \mathrm{Fe}-\mathrm{Cp}{ }^{\prime \prime} \mathrm{Co}-6 \mathrm{As}\right]^{+}\right)$.

EA: $\mathrm{C}_{54} \mathrm{H}_{88} \mathrm{Co}_{2} \mathrm{Fe}_{2} \mathrm{As}_{11} \times 0.85 \mathrm{CH}_{2} \mathrm{Cl}_{2}$ : calc [\%]: C: $35.38 ; \mathrm{H}: 4.85$; found [\%]: C: $35.44 ; \mathrm{H}: 4.66$.

EPR (X-band): (solid, 77 K) $g_{x}=2.29632, g_{y}=2.16718, g_{z}=2.07149, g_{\text {iso }}=2.17833$. 


\subsection{Synthesis of $\left[\left(\mathrm{Cp}^{\star} \mathrm{Fe}\right)_{2}\left(\mathrm{Cp} \mathrm{p}^{\prime \prime} \mathrm{Co}\right)\left(\mu_{3}, \eta^{2}: \eta^{2}: \eta^{2}-\mathrm{As}\right)_{2}\right)_{2}(7)$}

A solution of $3(1.05 \mathrm{~g}, 1.2237 \mathrm{mmol})$ in decaline was stirred under reflux for $3 \mathrm{~h}$ while the color changed to brown-green. The ${ }^{1} \mathrm{H}$ NMR of the reaction mixture reveals $\left[\mathrm{Cp}{ }^{*} \mathrm{Fe}\left(\eta^{5}-\mathrm{As} \mathrm{s}_{5}\right)\right](\mathbf{1} \mathbf{b})$, $\left[(\mathrm{Cp} \text { "'Co })_{2}\left(\mathrm{As}_{2}\right)_{2}\right](6)$ and $\left[\left(\mathrm{Cp}^{*} \mathrm{Fe}\right)_{2}(\mathrm{Cp}\right.$ "' $\left.\mathrm{Co})\left(\mu_{3}, \eta^{2}: \eta^{2}: \eta^{2}-\mathrm{As}_{3}\right)_{2}\right](7)$. The solvent was removed in vacuo. The residue was dissolved in $\mathrm{CH}_{2} \mathrm{Cl}_{2}, \mathrm{SiO}_{2}$ was added and the solvent removed in vacuo. The preabsorbed crude mixture was purified by column chromatography $\left(\mathrm{SiO}_{2}\right.$, hexane, $16 \times 3 \mathrm{~cm})$. Using hexane, a first dark green fraction (6) and a bright green fraction (1b) can be eluted. Using $\mathrm{CH}_{2} \mathrm{Cl}_{2}$, a dark brown fraction (7) can be eluted. $\mathbf{1 b}$ and $\mathbf{6}$ were disposed. The solvent was removed in vacuo. Compound 7 was dissolved in toluene and layered with acetonitrile at room temperature. After a few days, 7 can be obtained as dark brown blocks. The supernatant was decanted off and dried in vacuo.

\section{Compound 7:}

Yield: $203 \mathrm{mg}$ (90\% related to 1 using the stoichiometry of $3\left[\left(\mathrm{Cp}{ }^{*} \mathrm{Fe}\right)\left(\mathrm{Cp}{ }^{\prime \prime} \mathrm{Co}\right) \mathrm{As}_{5}\right] \rightarrow$ $\left.\left[\mathrm{Cp}^{*} \mathrm{FeAs}_{5}\right]+\left[\left(\mathrm{Cp} \mathrm{p}^{\prime \prime} \mathrm{Co}\right)_{2}\left(\mathrm{As}_{2}\right)_{2}\right]+\left[\left(\mathrm{Cp}{ }^{*} \mathrm{Fe}\right)_{2}\left(\mathrm{Cp} \mathrm{p}^{\prime \prime} \mathrm{Co}\right) \mathrm{As}_{6}\right]\right)$.

${ }^{1} \mathrm{H}$ NMR $\left(\mathrm{C}_{6} \mathrm{D}_{6}, 293 \mathrm{~K}\right): \delta[\mathrm{ppm}]=5.13\left(\mathrm{~s}, 2 \mathrm{H}, \mathrm{C}_{5} \mathrm{H}_{2}{ }^{\mathrm{t} B \mathrm{Bu}_{3}}\right), 1.84\left(\mathrm{~s}, 30 \mathrm{H}, \mathrm{C}_{5} \mathrm{Me}_{5}\right), 1.54(\mathrm{~s}, 18 \mathrm{H}$, $\left.\mathrm{C}_{5} \mathrm{H}_{2}{ }^{t} B u_{3}\right), 1.39\left(\mathrm{~s}, 9 \mathrm{H}, \mathrm{C}_{5} \mathrm{H}_{2}{ }^{t} B u_{3}\right)$.

LIFDI-MS (toluene): $m / z=1123.9\left(100 \%,\left[\mathrm{M}^{+}\right)\right.$.

EA: $\mathrm{C}_{37} \mathrm{H}_{59} \mathrm{CoFe}_{2} \mathrm{As}_{6}$ : calc [\%]: C: 39.54; H: 5.29; found [\%]: C: 39.79; H: 5.17. 


\subsection{Thermolysis reactions of $\left[\left(C p^{*} \mathrm{Fe}\right)\left(\mathrm{Cp} p^{\prime \prime} \mathrm{Co}\right)\left(\mu, \eta^{5}: \eta^{4}-\mathrm{As} 5\right)\right](3)$}

a-c): A solution of $50 \mathrm{mg} 3$ were dissolved in toluene $(\mathrm{a}, \mathrm{b})$ and xylene (c), respectively, and stirred for $93 \mathrm{~h}$ at a) $60^{\circ} \mathrm{C}$, b) $115^{\circ} \mathrm{C}$ and c) $140{ }^{\circ} \mathrm{C}$. Samples were each taken after $1,4,7$, $25,45,69$ and 93 hours, the solvent was removed in vacuo and taken up in $\mathrm{C}_{6} \mathrm{D}_{6}$ for NMR investigations. Selected spectra and graphs are depicted in chapter 2.6-2.8. 


\section{NMR spectroscopic investigations}

\section{$2.1\left[\left(\mathrm{Cp}{ }^{\star} \mathrm{Fe}\right)\left(\mathrm{Cp} \mathrm{p}^{\prime \prime} \mathrm{Co}\right)\left(\mu, \eta^{5}: \eta^{4}-\mathrm{As} 5\right)\right](3)$}

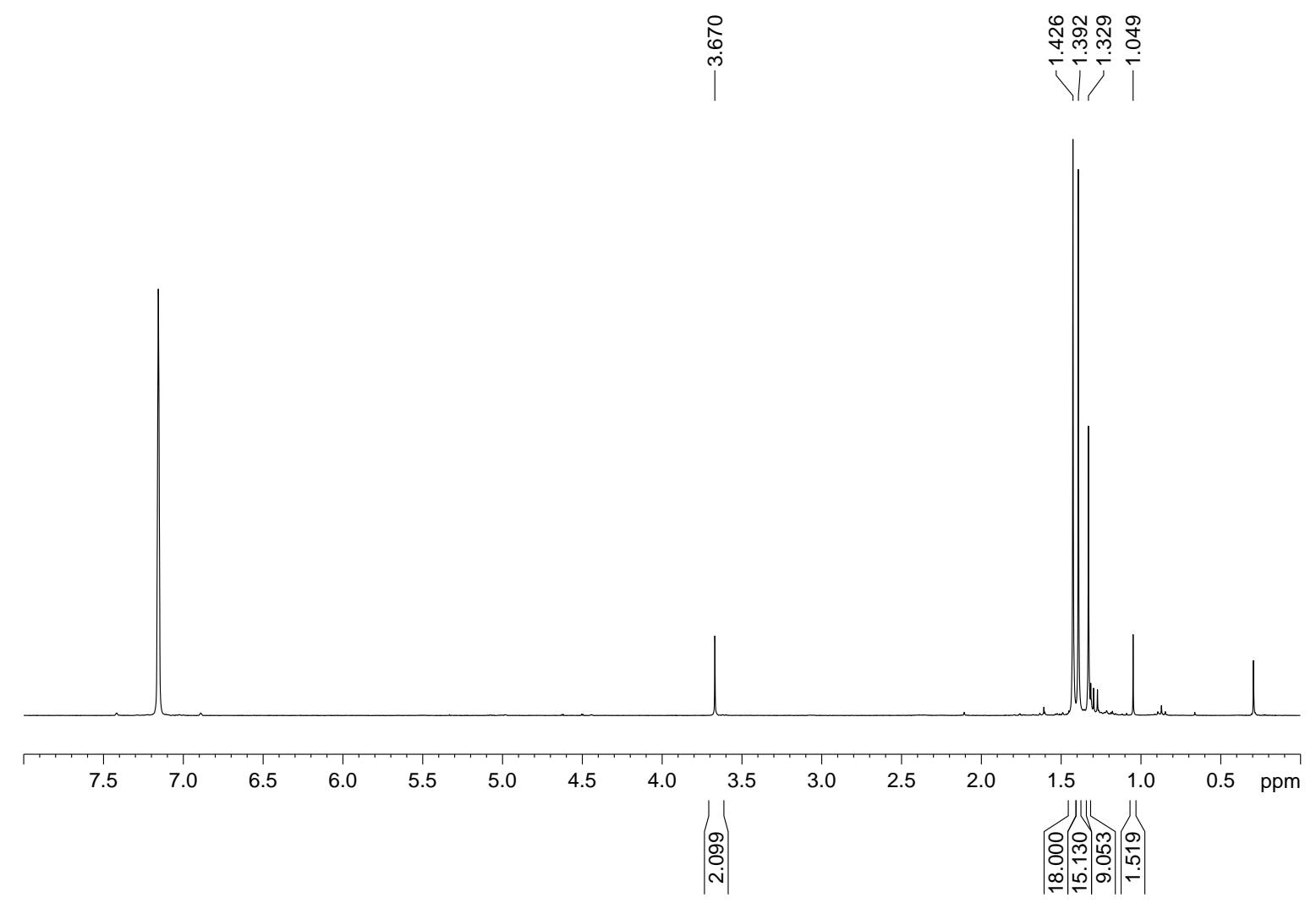

Figure S1: ${ }^{1} \mathrm{H}$ NMR spectrum in $\mathrm{C}_{6} \mathrm{D}_{6}$ at room temperature. Stoichiometric reaction of $\mathbf{1 b}$ and $\mathbf{2}$.

0
0
0
$n$

ษ్

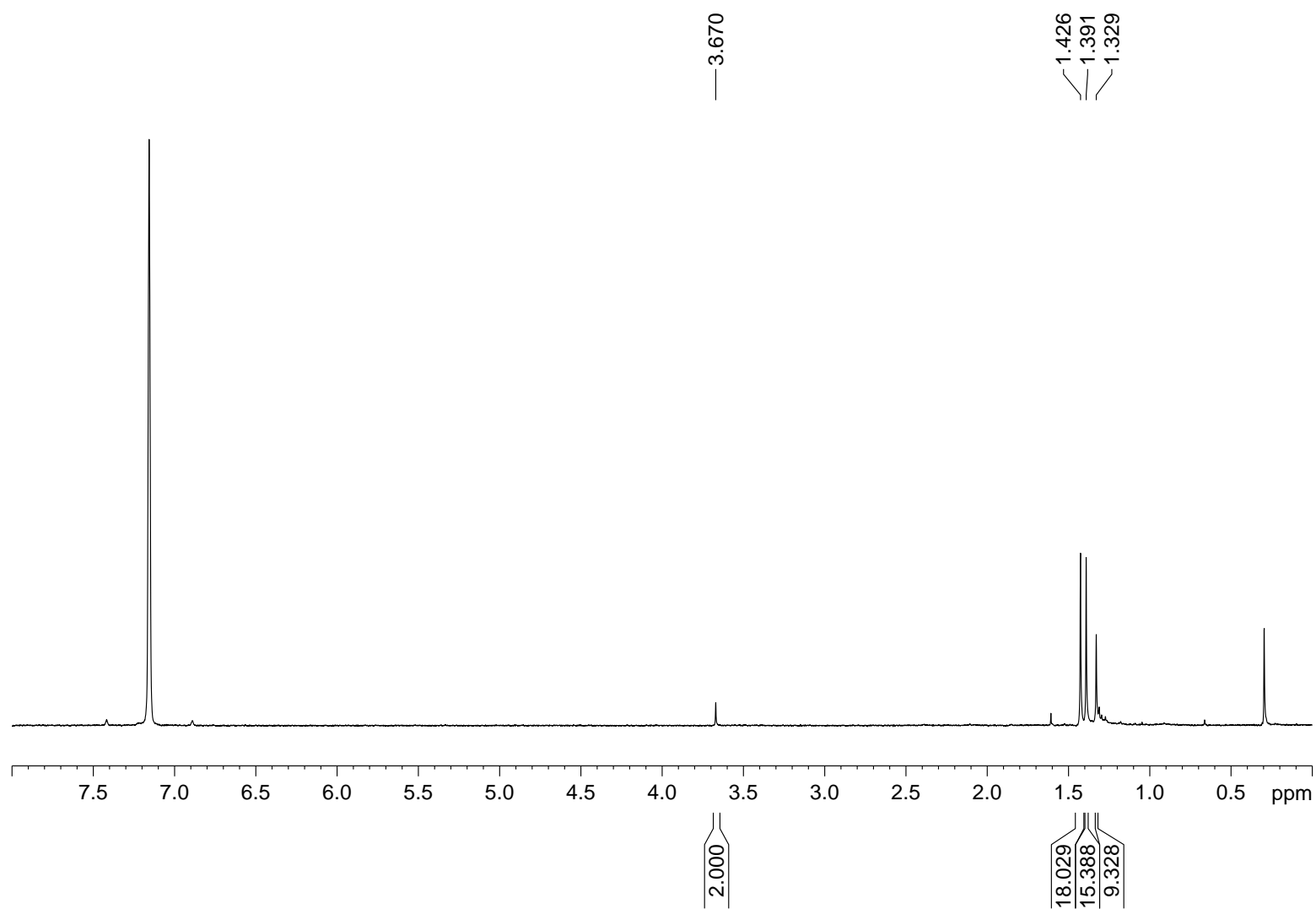

Figure S2: ${ }^{1} \mathrm{H}$ NMR spectrum of isolated dark green solid in $\mathrm{C}_{6} \mathrm{D}_{6}$ at room temperature. 


\section{$2.1\left[\left(C p^{*} \mathrm{Fe}\right)\left(\mathrm{Cp} p^{\prime \prime} \mathrm{Co}\right)\left(\mu, \eta^{3}: \eta^{3}-\mathrm{As} 3\right)\right](4)$}

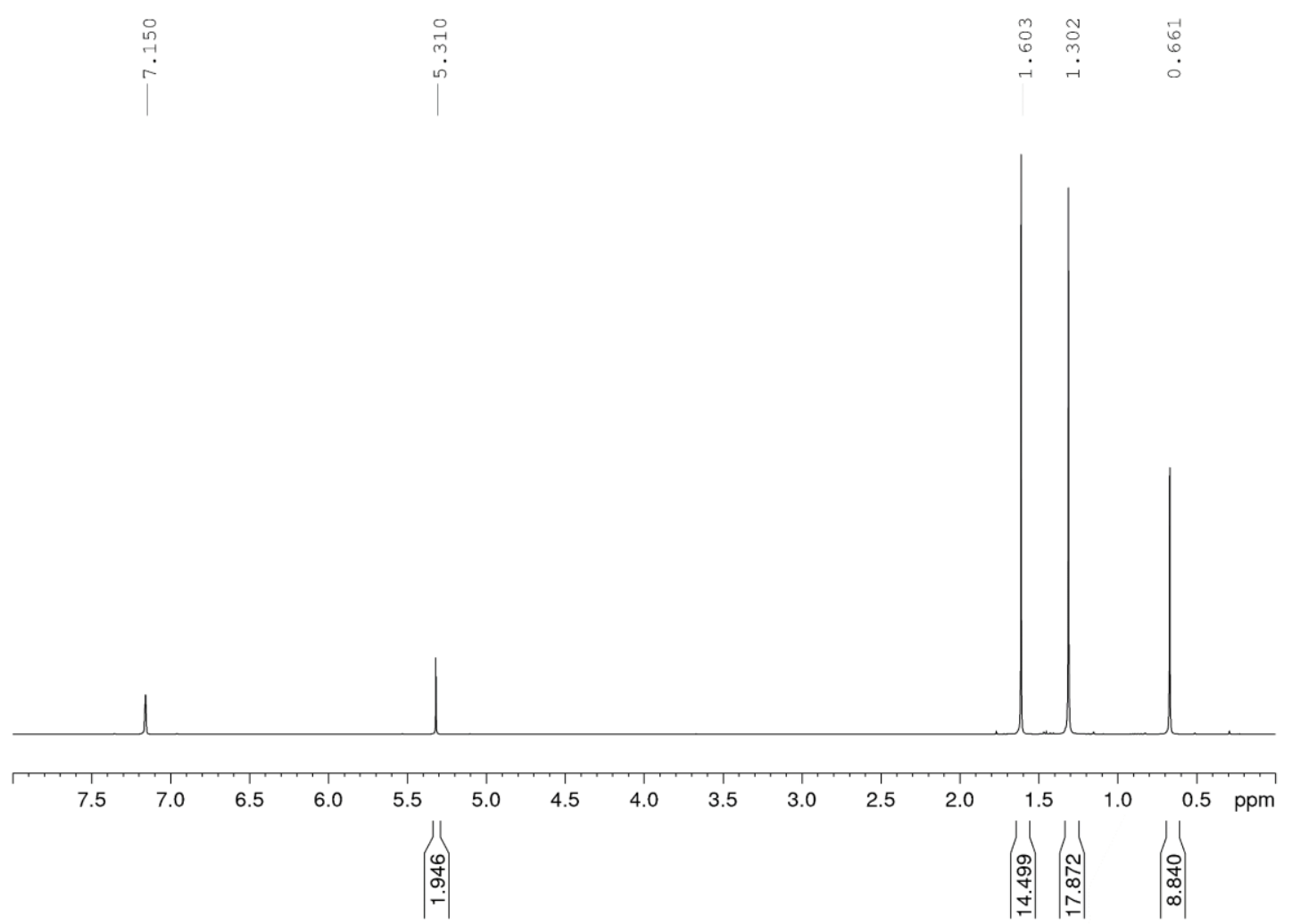

Figure S3: ${ }^{1} \mathrm{H}$ NMR spectrum of 4 in $\mathrm{C}_{6} \mathrm{D}_{6}$ at room temperature. 


\section{$2.3\left[\left(\mathrm{Cp}{ }^{*} \mathrm{Fe}\right)_{2}\left(\mathrm{Cp} \mathrm{p}^{\prime \prime} \mathrm{Co}\right)_{2}\left(\mu_{4,} \eta^{4}: \eta^{4}: \eta^{4}: \eta^{3}-\mathrm{As} \mathrm{s}_{11}\right)\right](5)$}

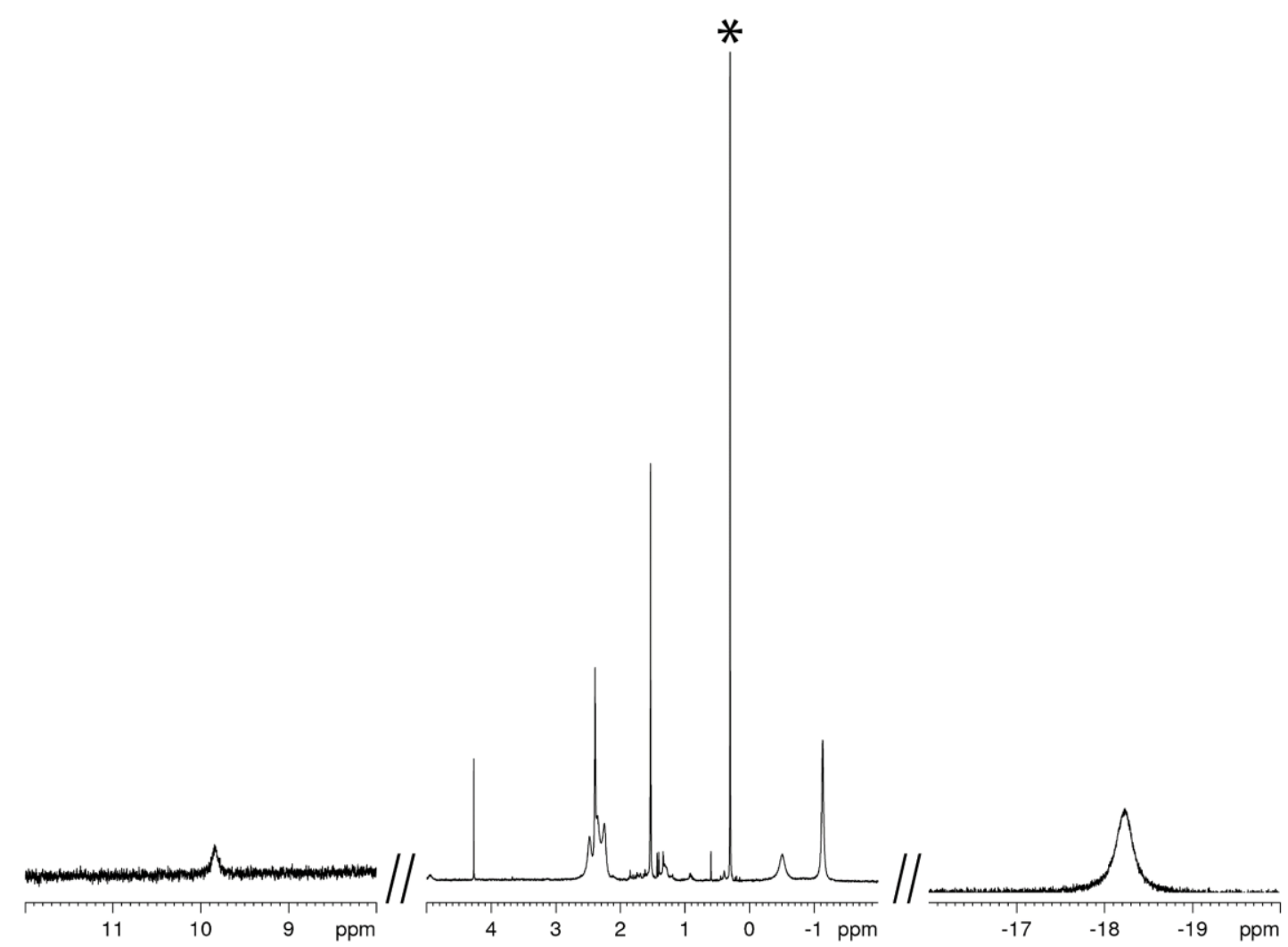

Figure S4: ${ }^{1} \mathrm{H}$ NMR spectrum of 5 in $\mathrm{C}_{6} \mathrm{D}_{6}$ at room temperature. Left and right part magnified for overview. Impurity of silicon grease $\left({ }^{*}\right)$. 


\section{$\left.2.4\left[\left(\mathrm{Cp}{ }^{\star} \mathrm{Fe}\right)_{2}(\mathrm{Cp}, " \mathrm{Co})\left(\mu_{3}, \eta^{2}: \eta^{2}: \eta^{2}-\mathrm{As}\right)_{3}\right)_{2}\right](7)$}

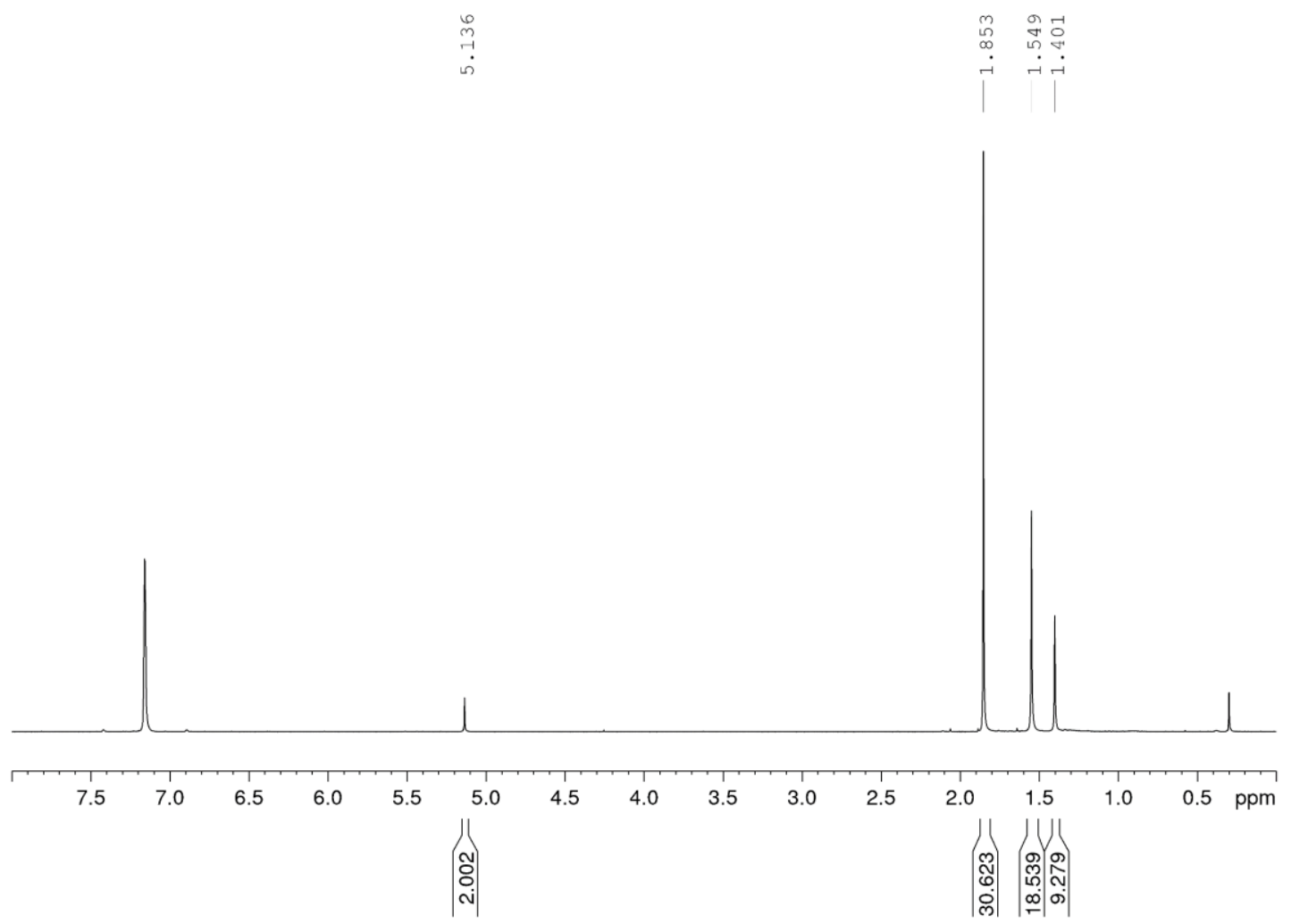

Figure S5: $1 \mathrm{H}$ NMR spectrum of 7 in $\mathrm{C}_{6} \mathrm{D}_{6}$ at room temperature. 


\subsection{Fragmentation of 3 with acetonitrile}

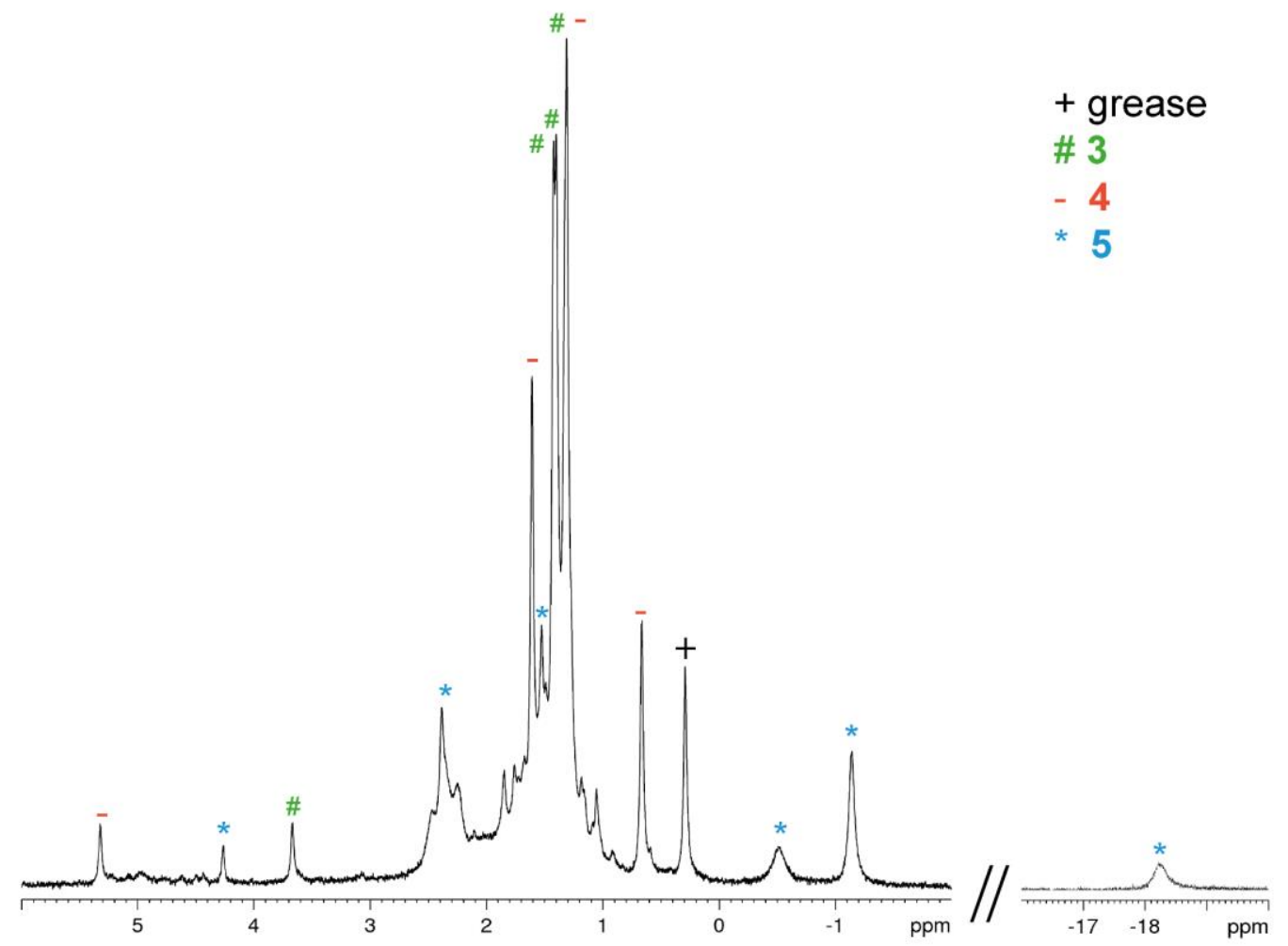

Figure S6: ${ }^{1} \mathrm{H}$ NMR spectrum of the reaction mixture three days after the addition of $\mathrm{MeCN}$ in $\mathrm{C}_{6} \mathrm{D}_{6}$ at room temperature. 


\subsection{Thermolysis of 3 in toluene at $60^{\circ} \mathrm{C}$}

Since $\mathbf{1 b}$ is the only compound which is present in all spectra, it was chosen to be the reference.

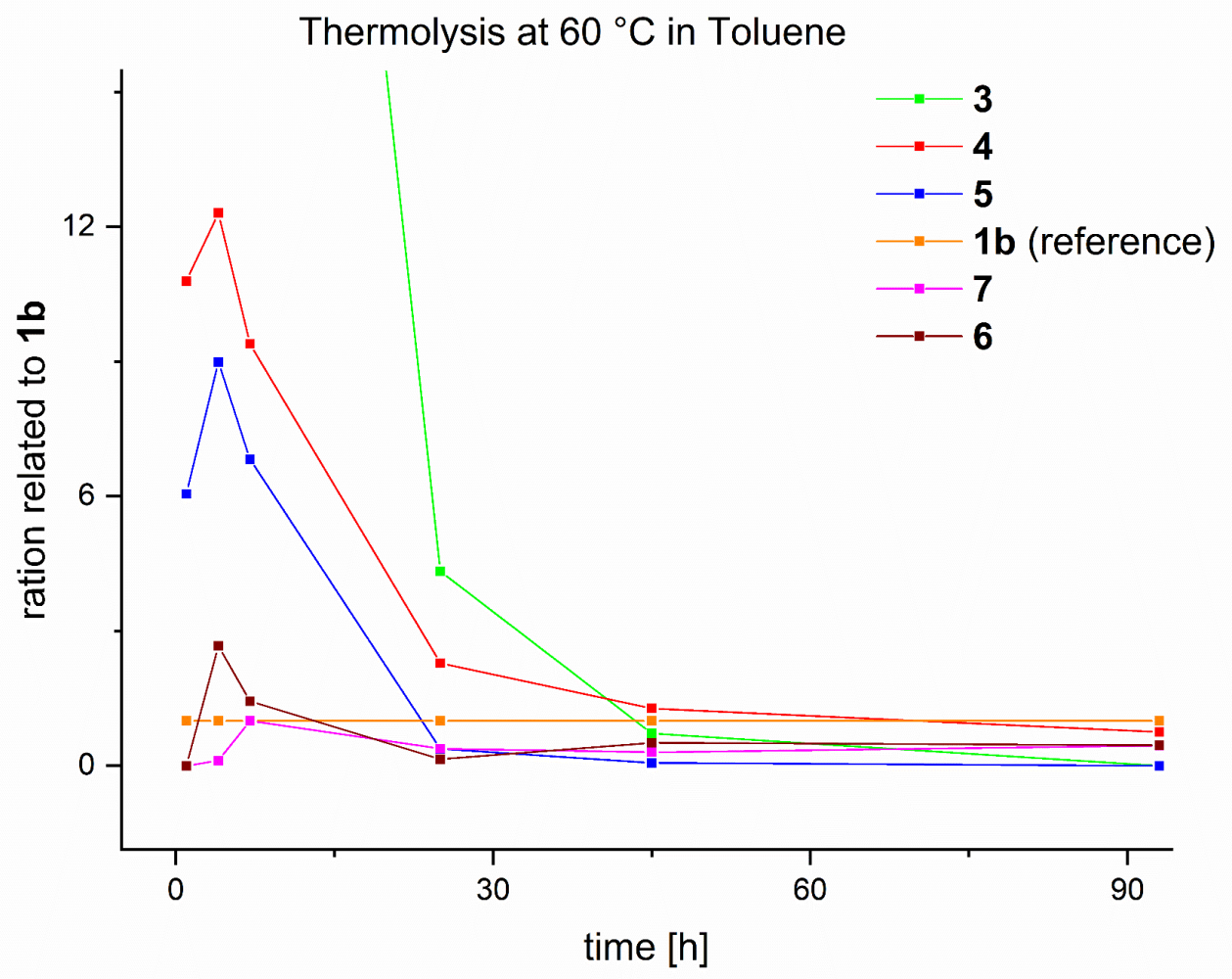

Figure S7: Plotted relative integrals for all compounds referenced to $\mathbf{1 b}$

Table S1: Integral ratios of all compounds related to $\mathbf{1 b}$.

\begin{tabular}{c|cccccc} 
Time $[\mathrm{h}]$ & $\mathbf{3}$ & $\mathbf{4}$ & $\mathbf{5}$ & $\mathbf{7}$ & $\mathbf{1 b}$ & $\mathbf{6}$ \\
\hline 1 & 131.579 & 10.789 & 6.053 & 0 & 1 & 0 \\
4 & 96.154 & 12.308 & 8.99 & 0.115 & 1 & 2.663 \\
7 & 43.478 & 9.391 & 6.822 & 1 & 1 & 1.435 \\
25 & 4.329 & 2.281 & 0.377 & 0.381 & 1 & 0.146 \\
45 & 0.715 & 1.276 & 0.061 & 0.299 & 1 & 0.511 \\
93 & 0 & 0.745 & 0 & 0.445 & 1 & 0.454
\end{tabular}




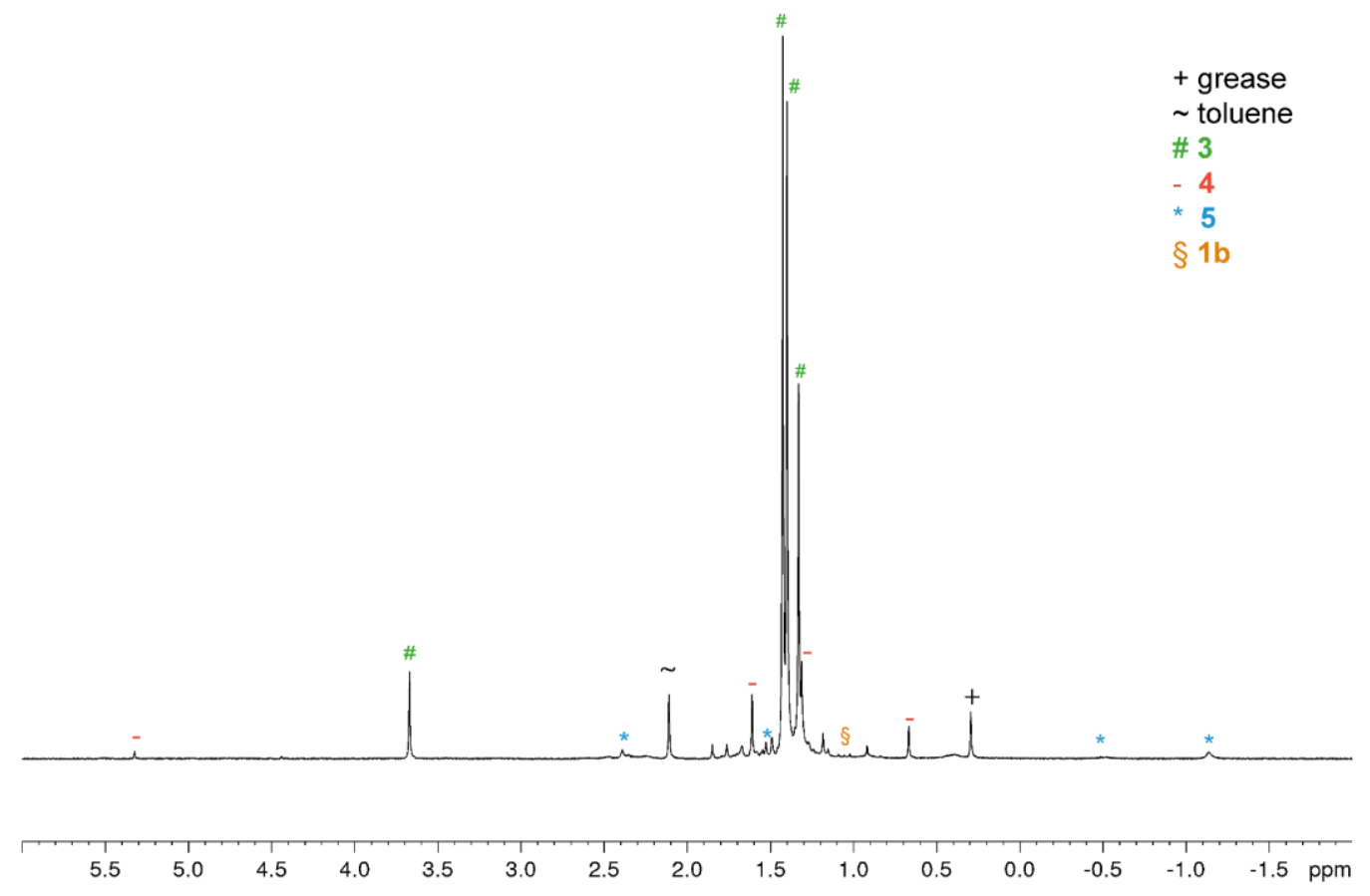

Figure S8: ${ }^{1} \mathrm{H}$ NMR spectrum of the reaction mixture in $\mathrm{C}_{6} \mathrm{D}_{6}$ at room temperature after $1 \mathrm{~h}$.

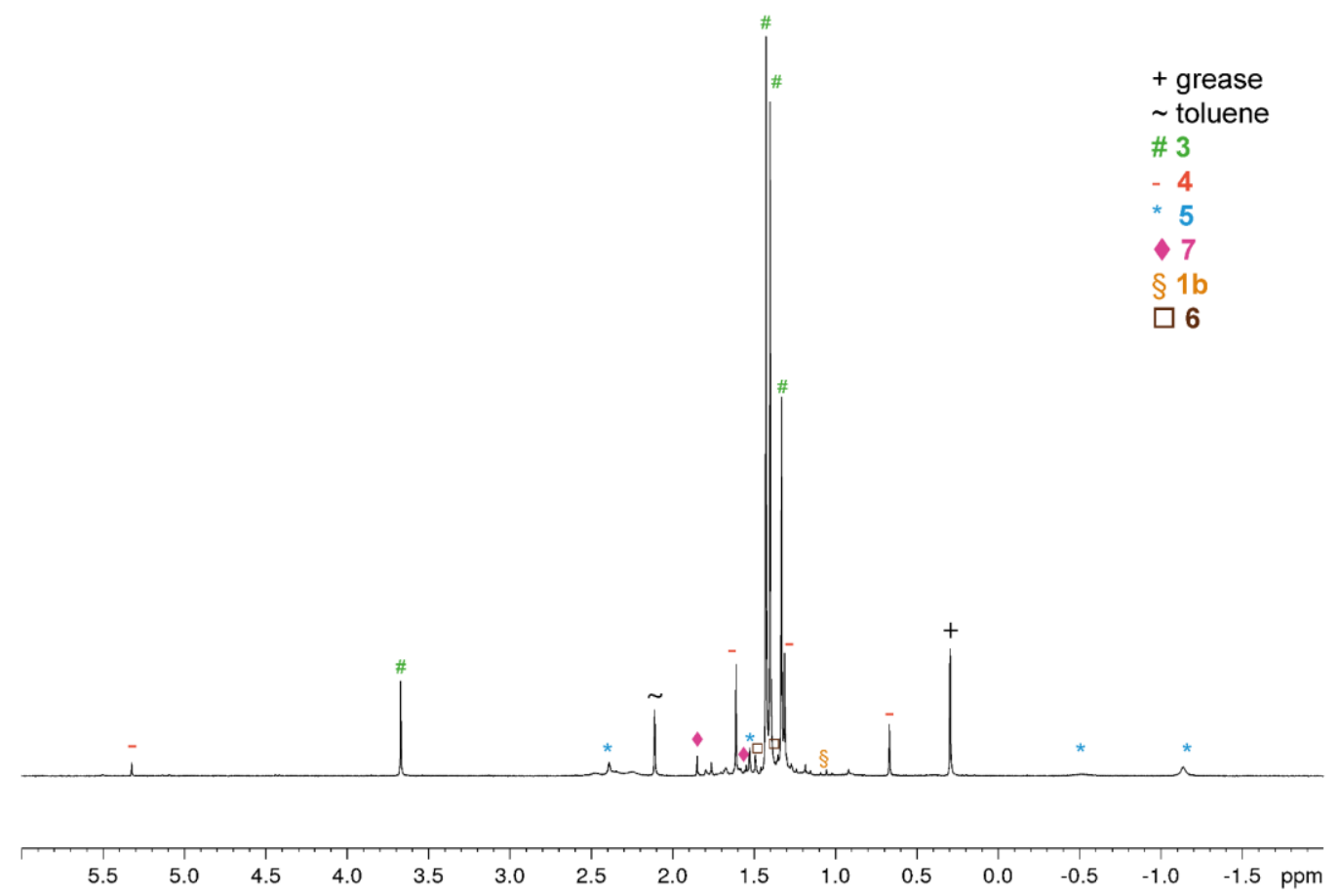

Figure S9: ${ }^{1} \mathrm{H}$ NMR spectrum of the reaction mixture in $\mathrm{C}_{6} \mathrm{D}_{6}$ at room temperature after $4 \mathrm{~h}$. 


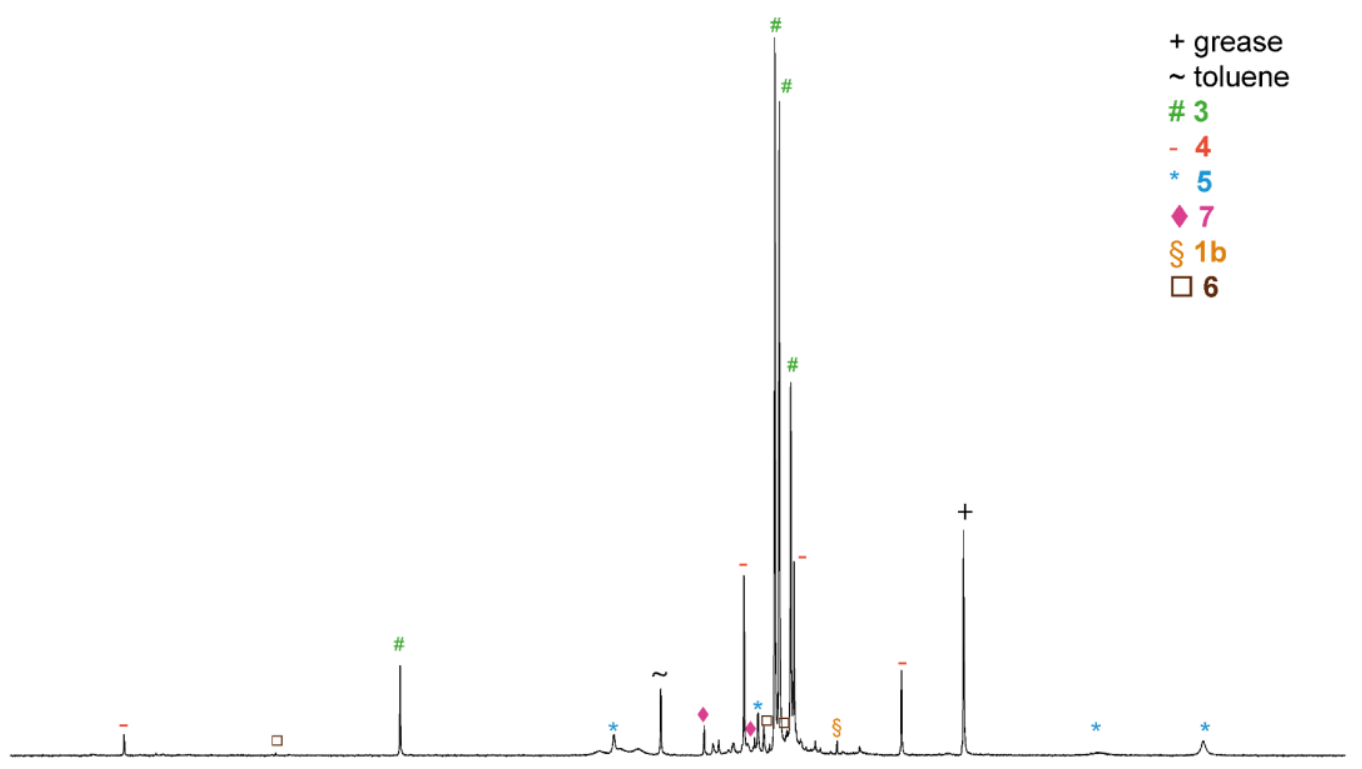

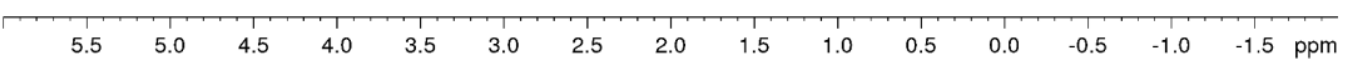

Figure S10: ${ }^{1} \mathrm{H}$ NMR spectrum of the reaction mixture in $\mathrm{C}_{6} \mathrm{D}_{6}$ at room temperature after $7 \mathrm{~h}$.

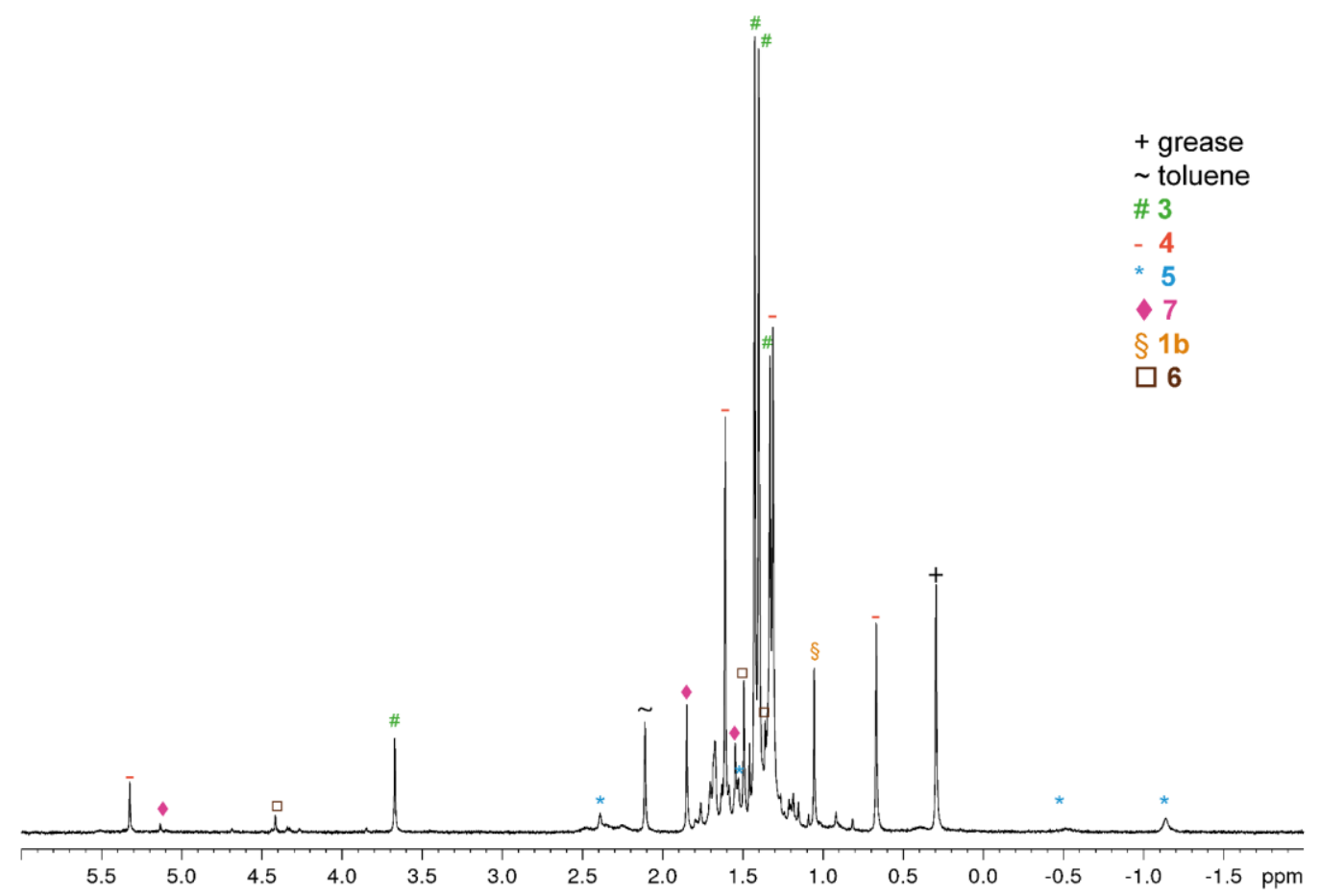

Figure S11: ${ }^{1} \mathrm{H}$ NMR spectrum of the reaction mixture in $\mathrm{C}_{6} \mathrm{D}_{6}$ at room temperature after $25 \mathrm{~h}$. 


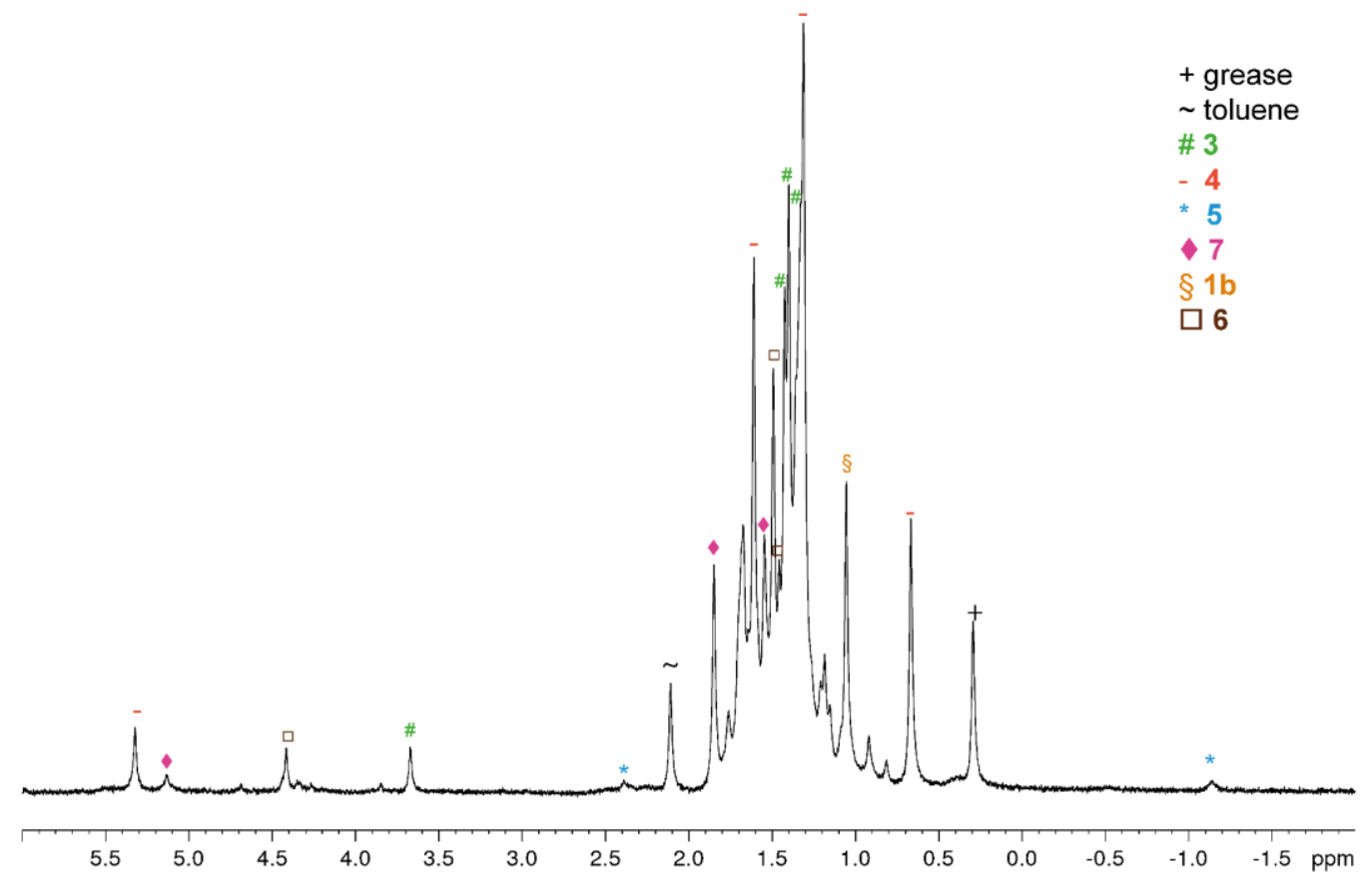

Figure S12: ${ }^{1} \mathrm{H}$ NMR spectrum of the reaction mixture in $\mathrm{C}_{6} \mathrm{D}_{6}$ at room temperature after $45 \mathrm{~h}$.

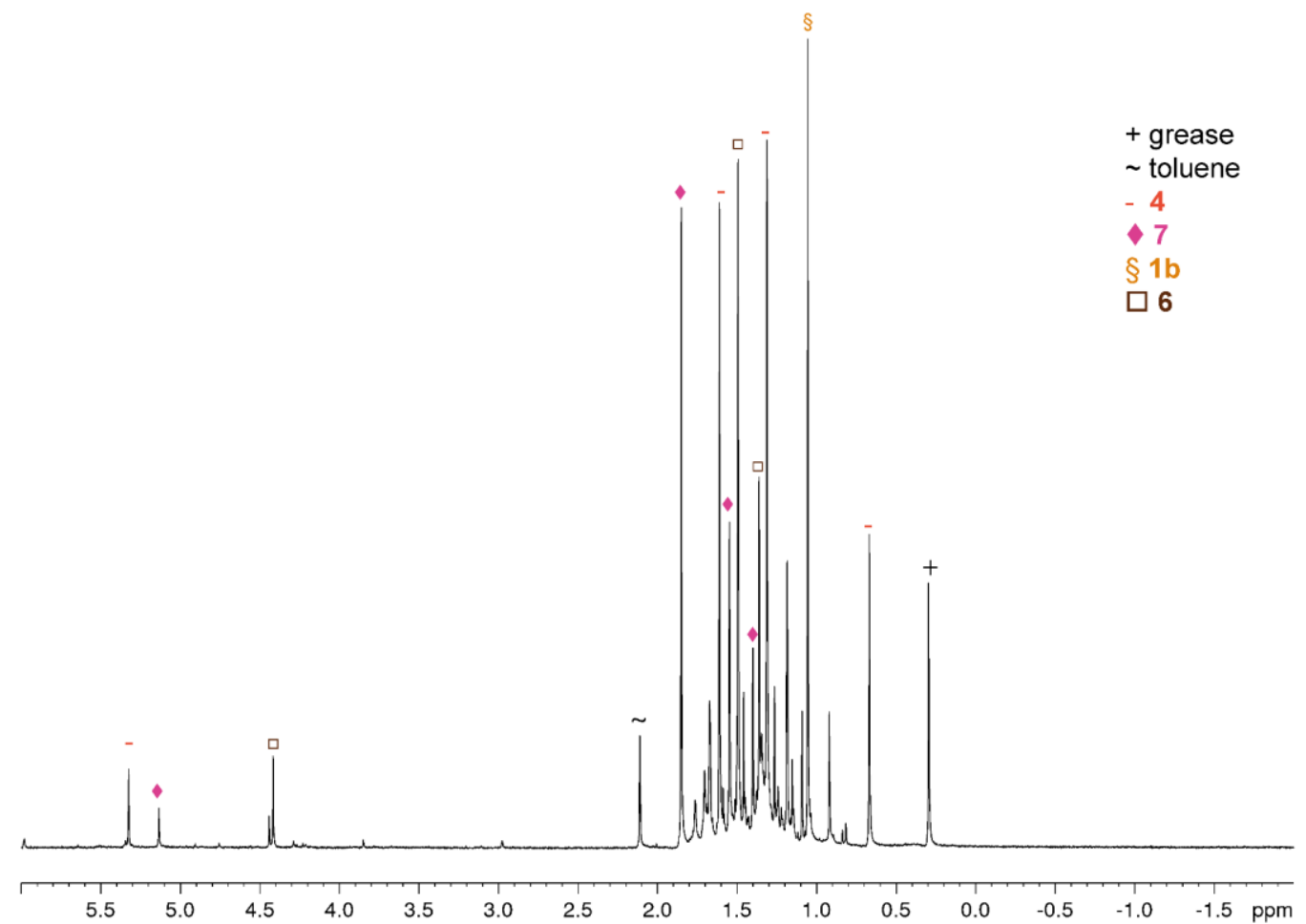

Figure S13: ${ }^{1} \mathrm{H}$ NMR spectrum of the reaction mixture in $\mathrm{C}_{6} \mathrm{D}_{6}$ at room temperature after $93 \mathrm{~h}$. 


\subsection{Thermolysis of 3 in toluene at $115^{\circ} \mathrm{C}$}

Since $\mathbf{1 b}$ is the only compound which is present in all spectra, it was chosen to be the reference.

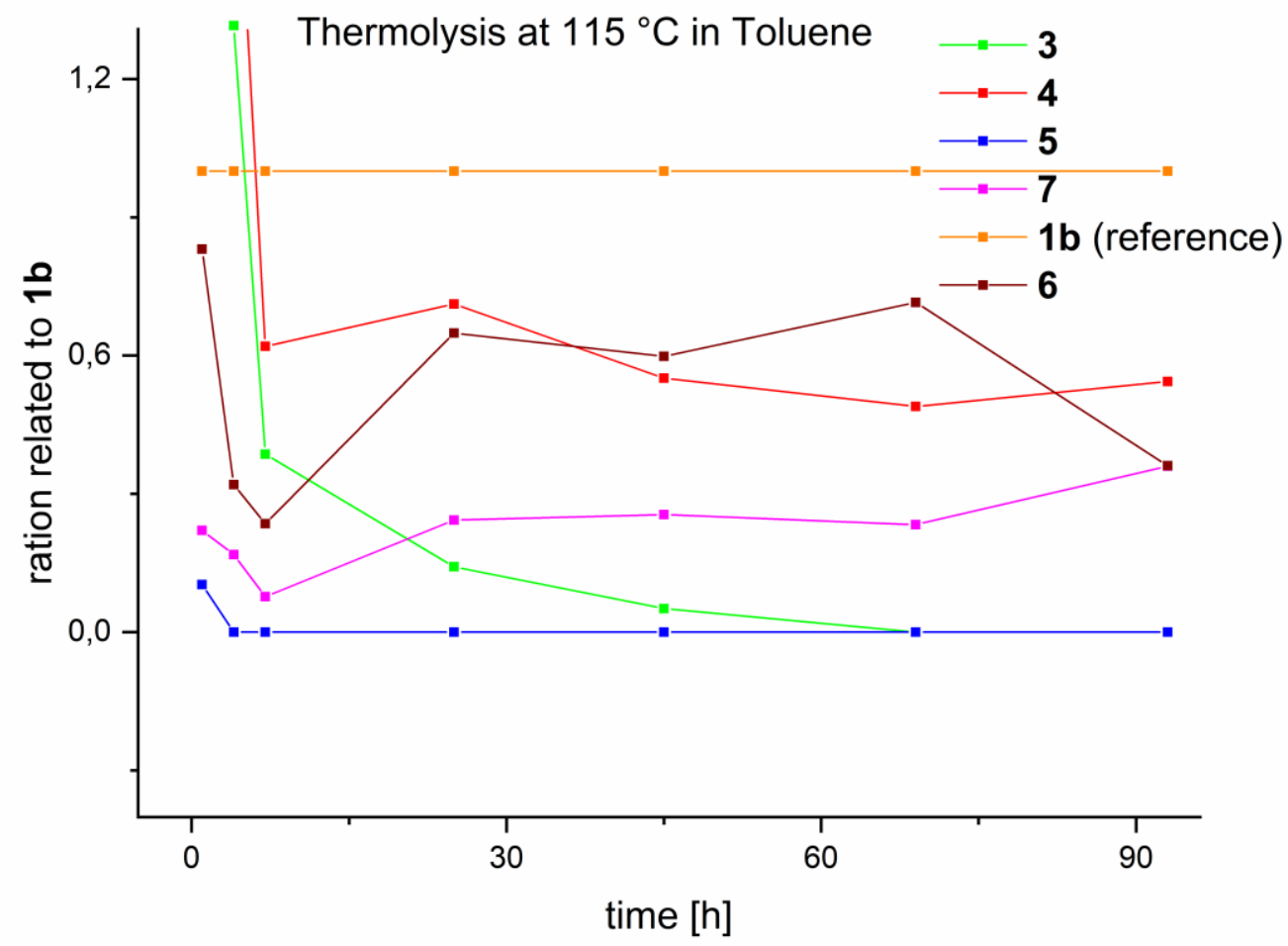

Figure S14: Plotted relative integrals for all compounds referenced to $\mathbf{1 b}$.

Table S2: Integral ratios of all compounds related to $\mathbf{1 b}$.

\begin{tabular}{c|cccccc} 
Time $[\mathrm{h}]$ & $\mathbf{3}$ & $\mathbf{4}$ & $\mathbf{5}$ & $\mathbf{7}$ & $\mathbf{1 b}$ & $\mathbf{6}$ \\
\hline 1 & 4.329 & 3.281 & 0.103 & 0.221 & 1 & 0.831 \\
4 & 1.316 & 1.845 & 0 & 0.168 & 1 & 0.32 \\
7 & 0.386 & 0.62 & 0 & 0.077 & 1 & 0.235 \\
25 & 0.142 & 0.712 & 0 & 0.243 & 1 & 0.649 \\
45 & 0.051 & 0.551 & 0 & 0.255 & 1 & 0.598 \\
69 & 0 & 0.4894 & 0 & 0.2331 & 1 & 0.7154 \\
93 & 0 & 0.5438 & 0 & 0.3601 & 1 & 0.361
\end{tabular}




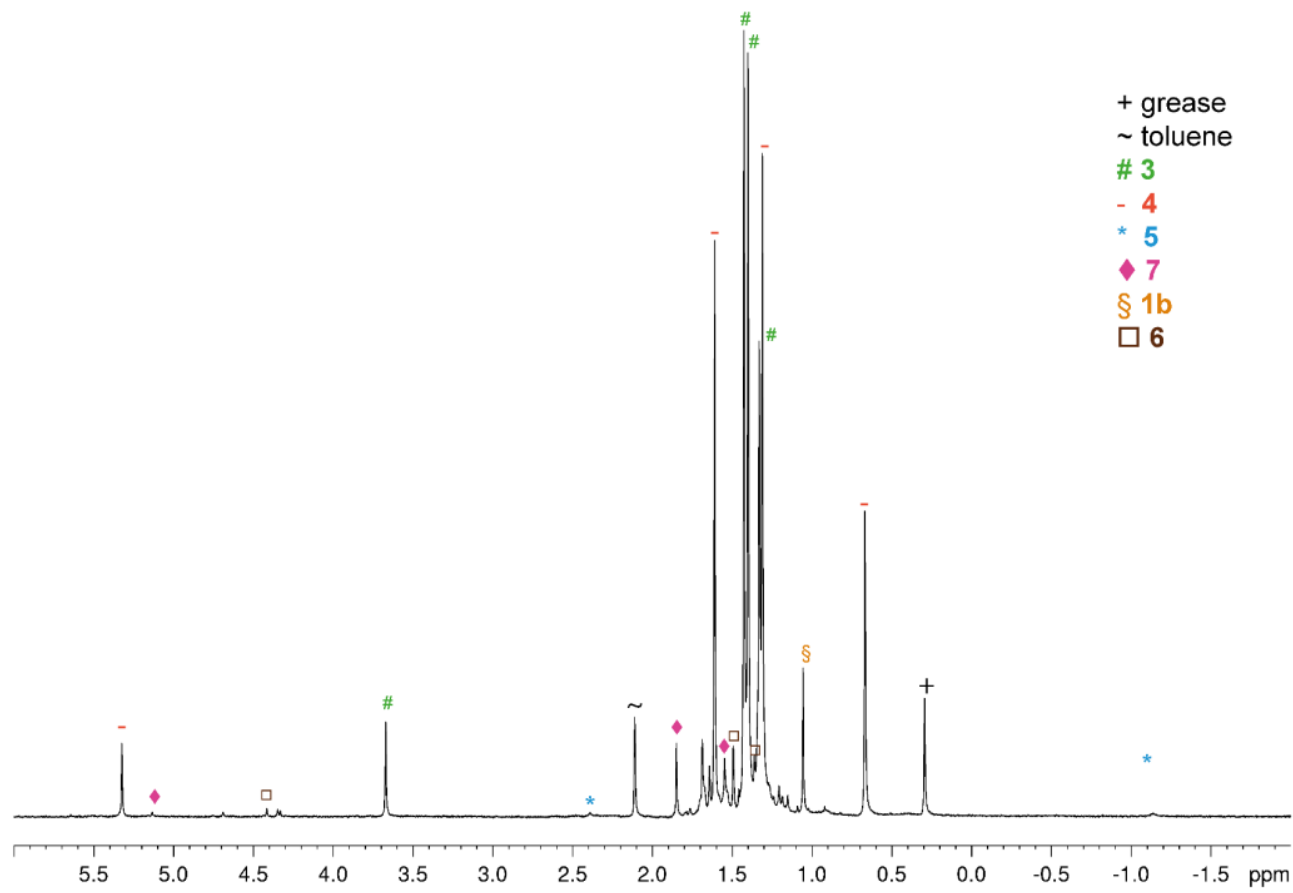

Figure S15: ${ }^{1} \mathrm{H}$ NMR spectrum of the reaction mixture in $\mathrm{C}_{6} \mathrm{D}_{6}$ at room temperature after $1 \mathrm{~h}$.

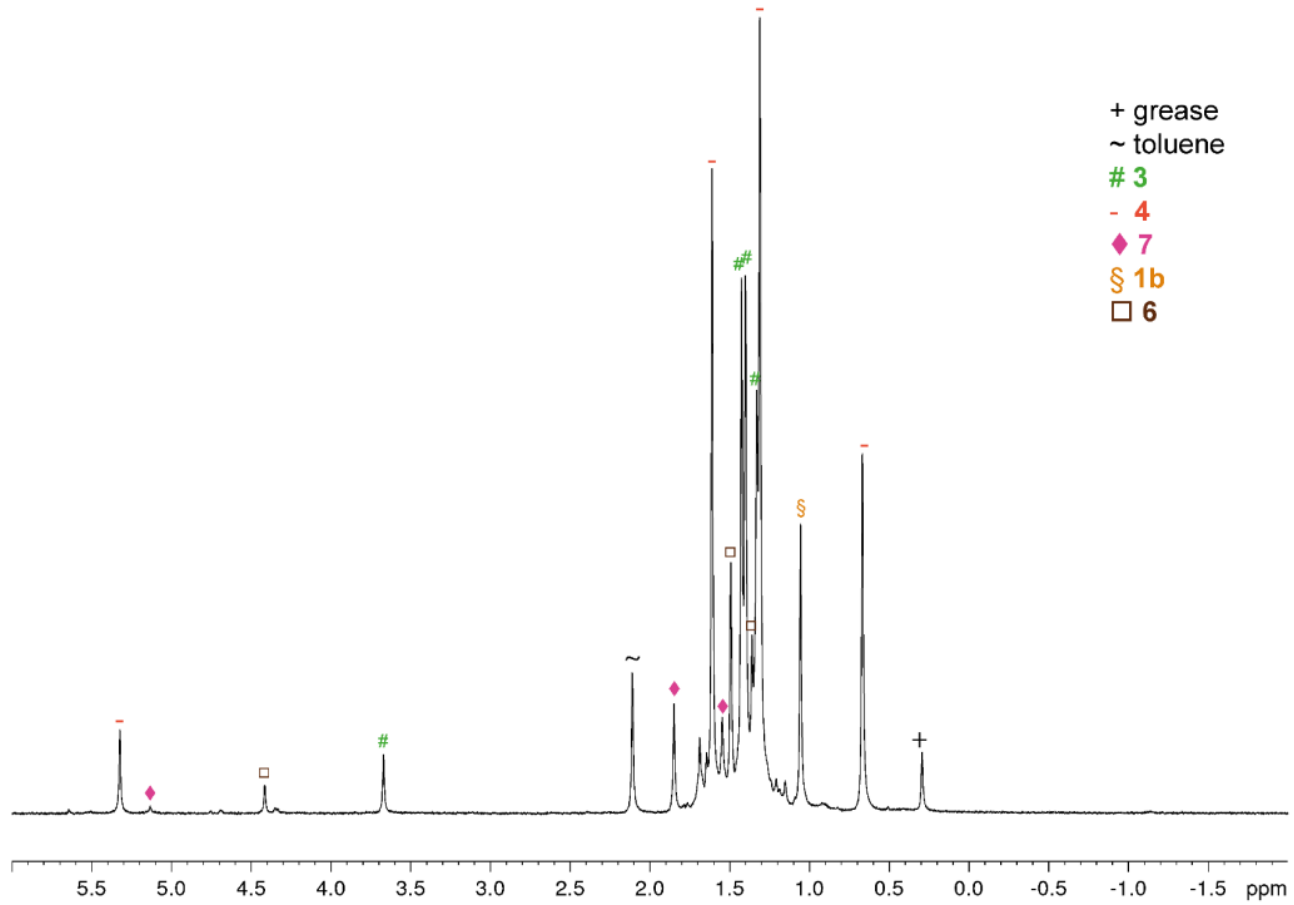

Figure S16: ${ }^{1} \mathrm{H}$ NMR spectrum of the reaction mixture in $\mathrm{C}_{6} \mathrm{D}_{6}$ at room temperature after $4 \mathrm{~h}$. 


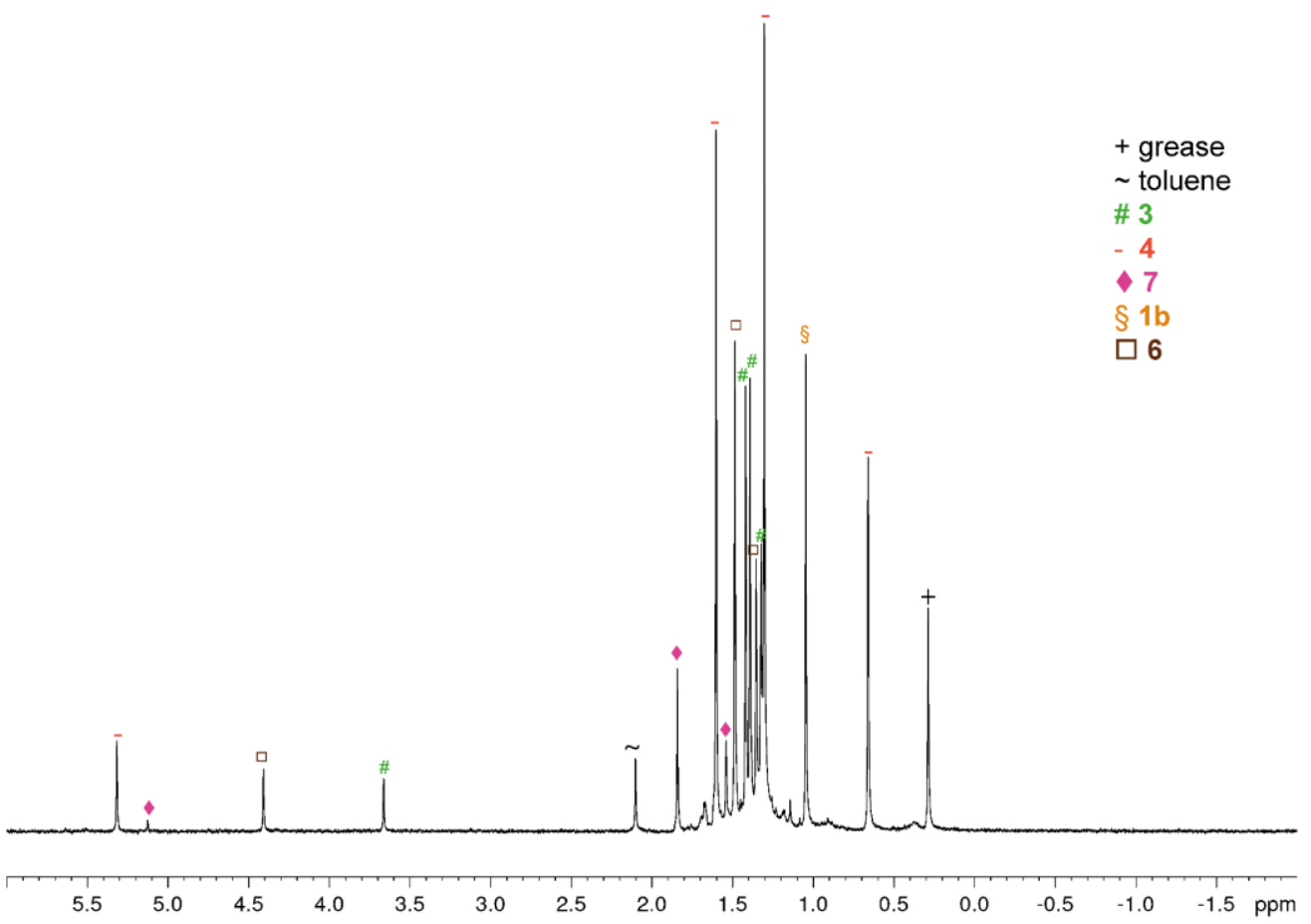

Figure S17: ${ }^{1} \mathrm{H}$ NMR spectrum of the reaction mixture in $\mathrm{C}_{6} \mathrm{D}_{6}$ at room temperature after $7 \mathrm{~h}$.

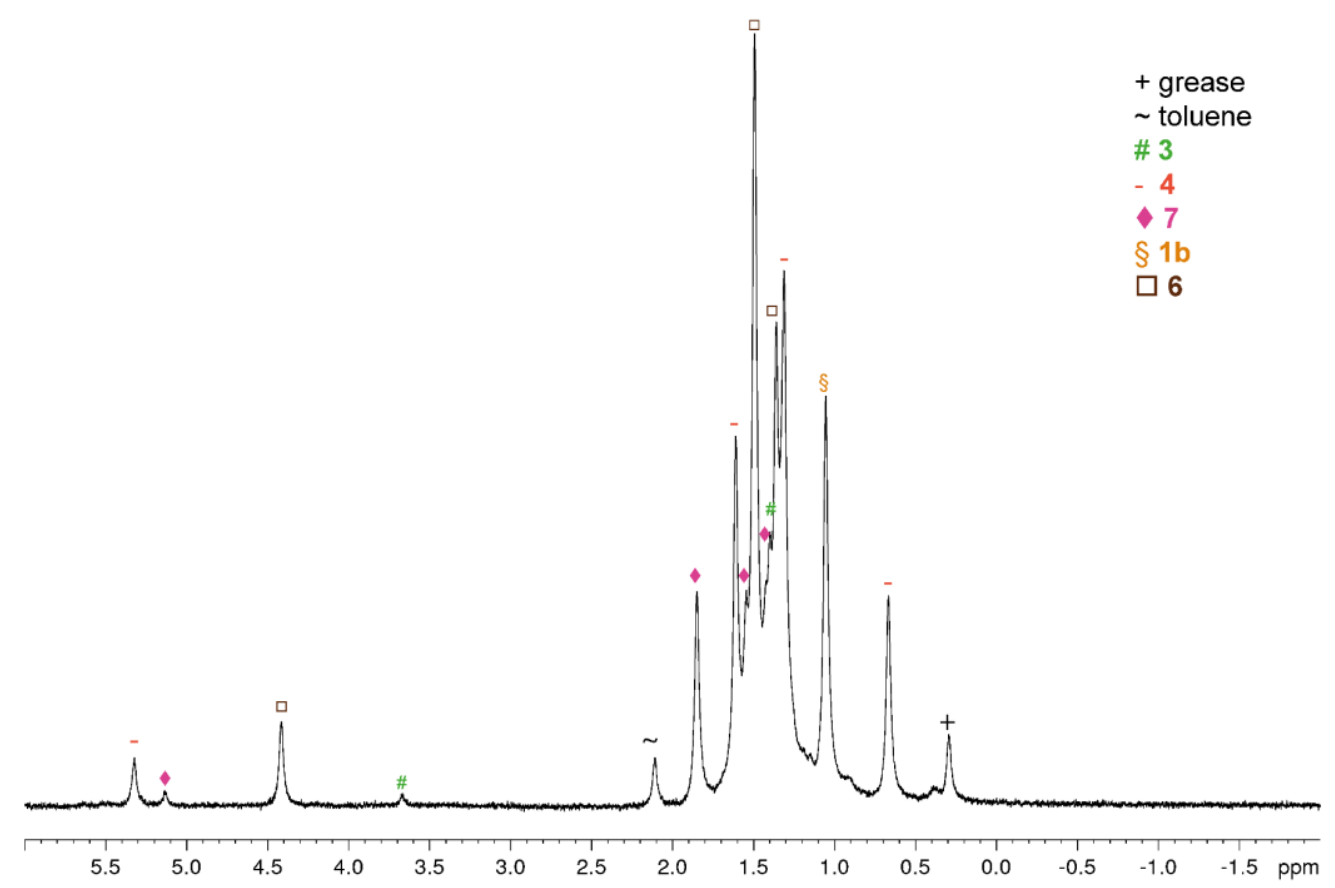

Figure S18: ${ }^{1} \mathrm{H}$ NMR spectrum of the reaction mixture in $\mathrm{C}_{6} \mathrm{D}_{6}$ at room temperature after $25 \mathrm{~h}$. 


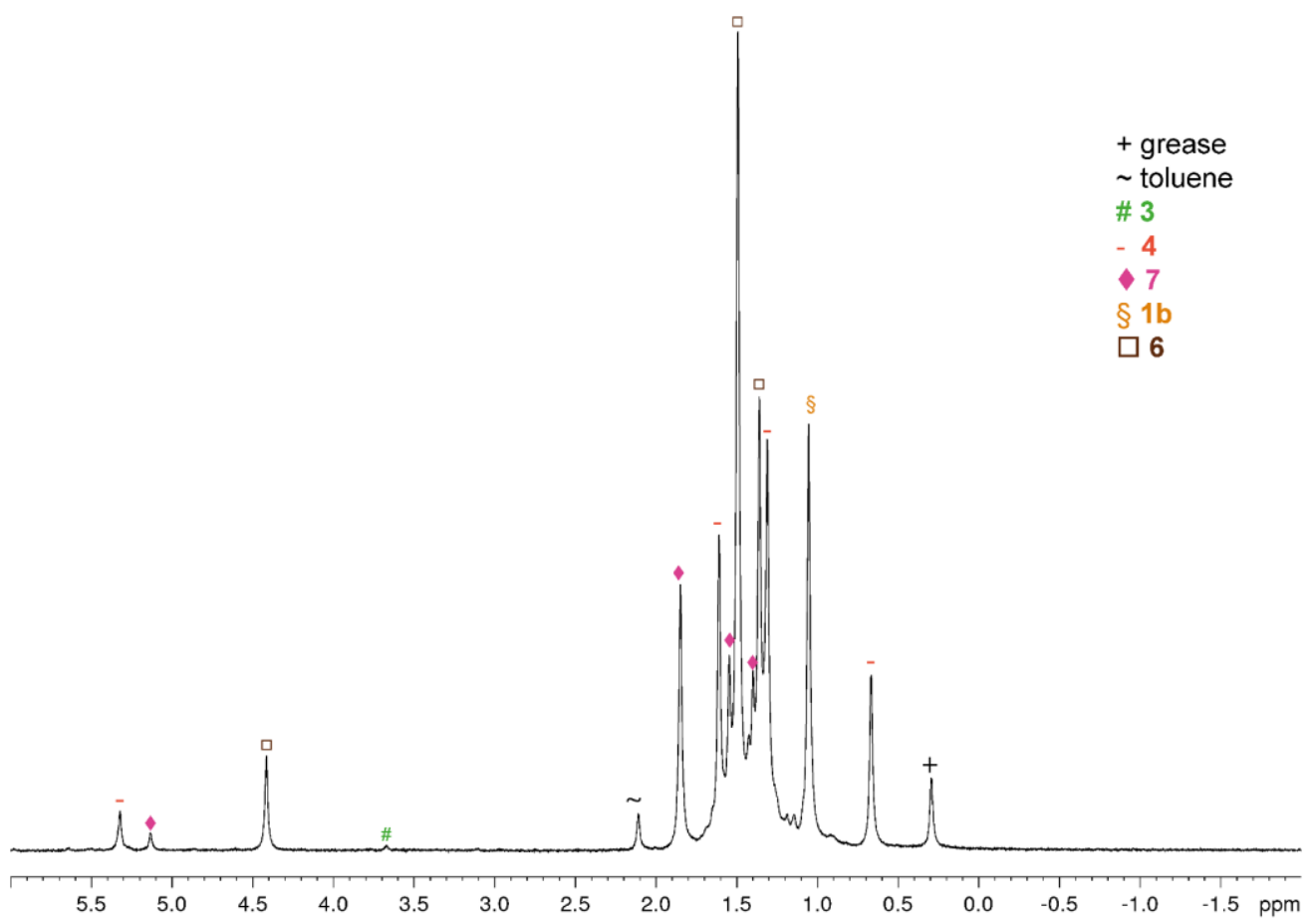

Figure S19: ${ }^{1} \mathrm{H}$ NMR spectrum of the reaction mixture in $\mathrm{C}_{6} \mathrm{D}_{6}$ at room temperature after $45 \mathrm{~h}$.

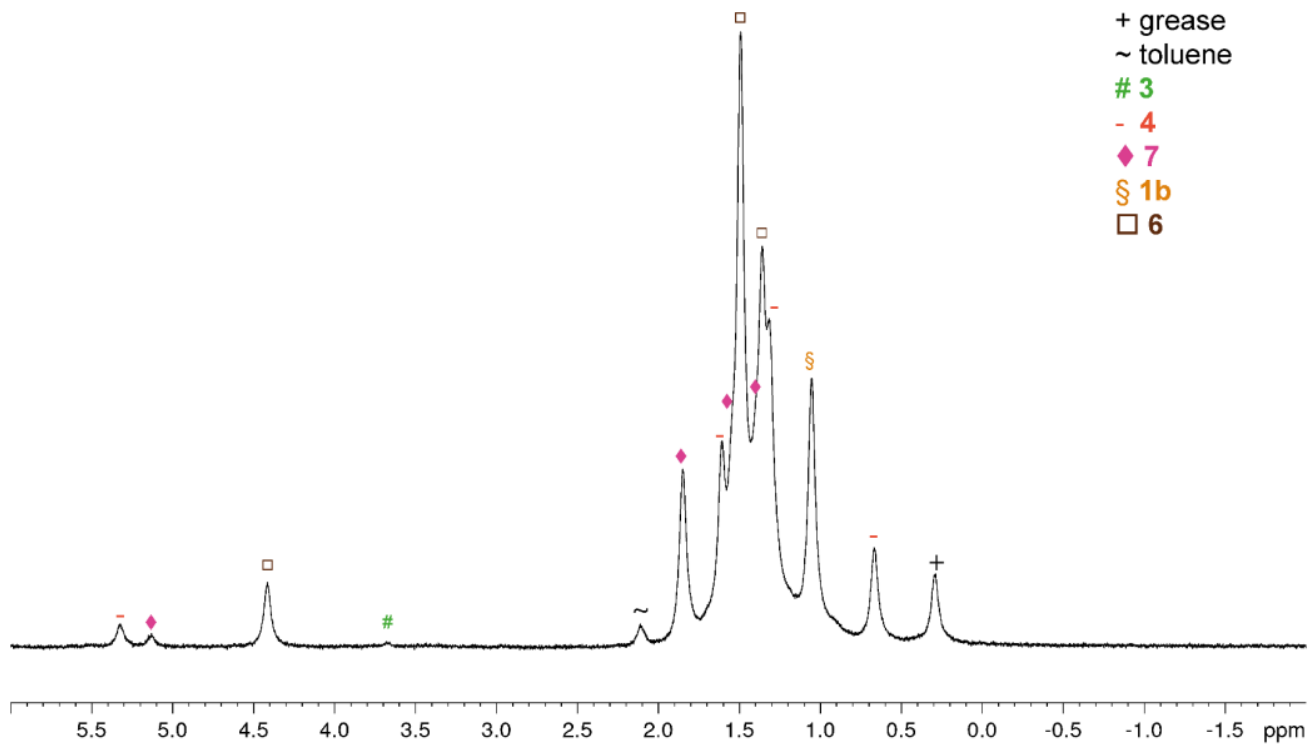

Figure S20: ${ }^{1} \mathrm{H}$ NMR spectrum of the reaction mixture in $\mathrm{C}_{6} \mathrm{D}_{6}$ at room temperature after $69 \mathrm{~h}$. 


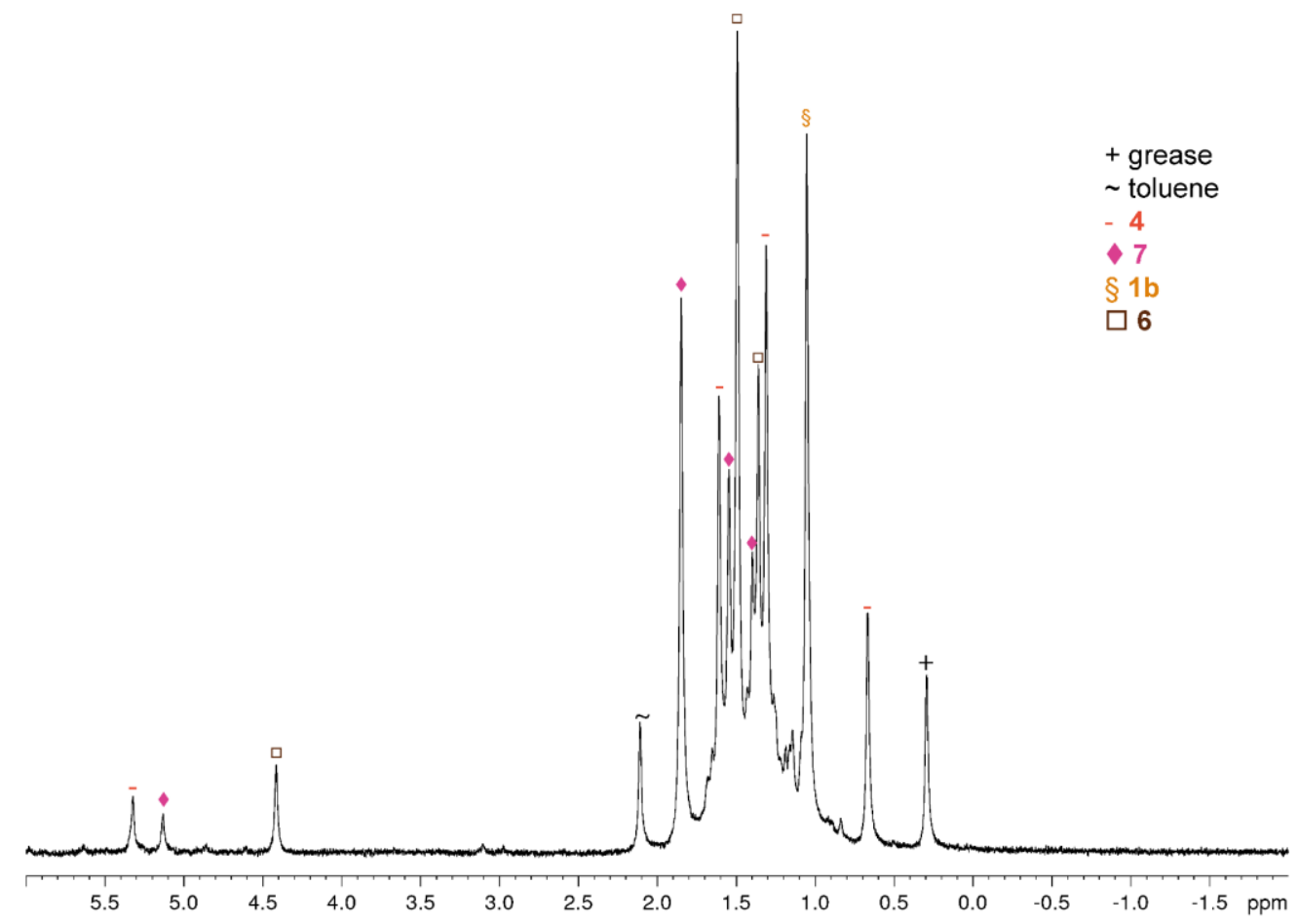

Figure S21: ${ }^{1} \mathrm{H}$ NMR spectrum of the reaction mixture in $\mathrm{C}_{6} \mathrm{D}_{6}$ at room temperature after $93 \mathrm{~h}$. 


\subsection{Thermolysis of 3 in xylene at $140{ }^{\circ} \mathrm{C}$}

Since $\mathbf{1 b}$ is the only compound which is present in all spectra, it was chosen to be the reference.

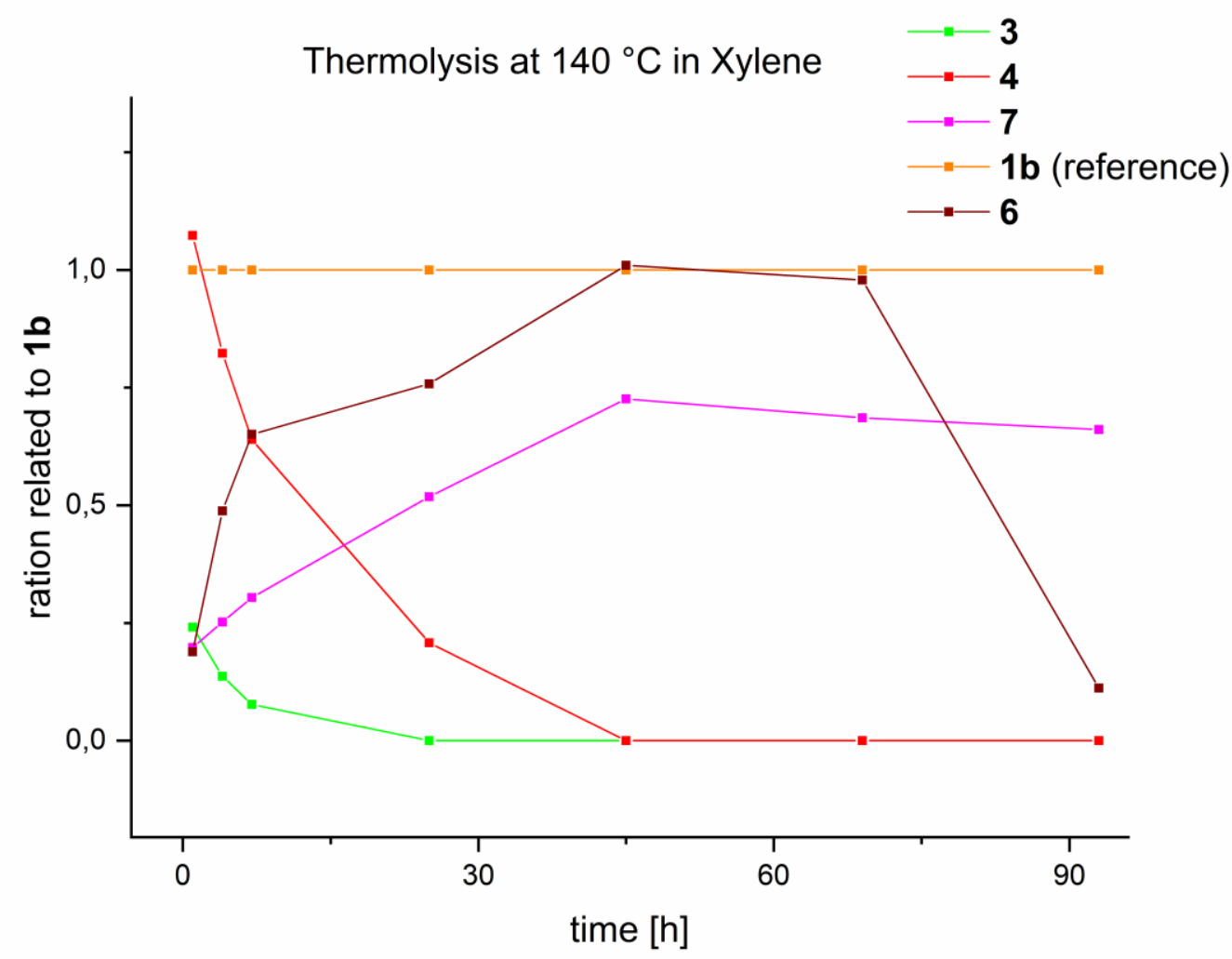

Figure S22: Plotted relative integrals for all compounds referenced to $\mathbf{1 b}$.

Table S3: Integral ratios of all compounds related to $\mathbf{1 b}$.

\begin{tabular}{c|cccccc} 
Time $[\mathrm{h}]$ & $\mathbf{3}$ & $\mathbf{4}$ & $\mathbf{5}$ & $\mathbf{7}$ & $\mathbf{1 b}$ & $\mathbf{6}$ \\
\hline 1 & 0.241 & 1.073 & 0 & 0.198 & 1 & 0.189 \\
4 & 0.137 & 0.823 & 0 & 0.252 & 1 & 0.488 \\
7 & 0.077 & 0.64 & 0 & 0.304 & 1 & 0.651 \\
25 & 0 & 0.208 & 0 & 0.518 & 1 & 0.758 \\
45 & 0 & 0 & 0 & 0.726 & 1 & 1.01 \\
69 & 0 & 0 & 0 & 0.686 & 1 & 0.9782 \\
93 & 0 & 0 & 0 & 0.6606 & 1 & 0.112
\end{tabular}




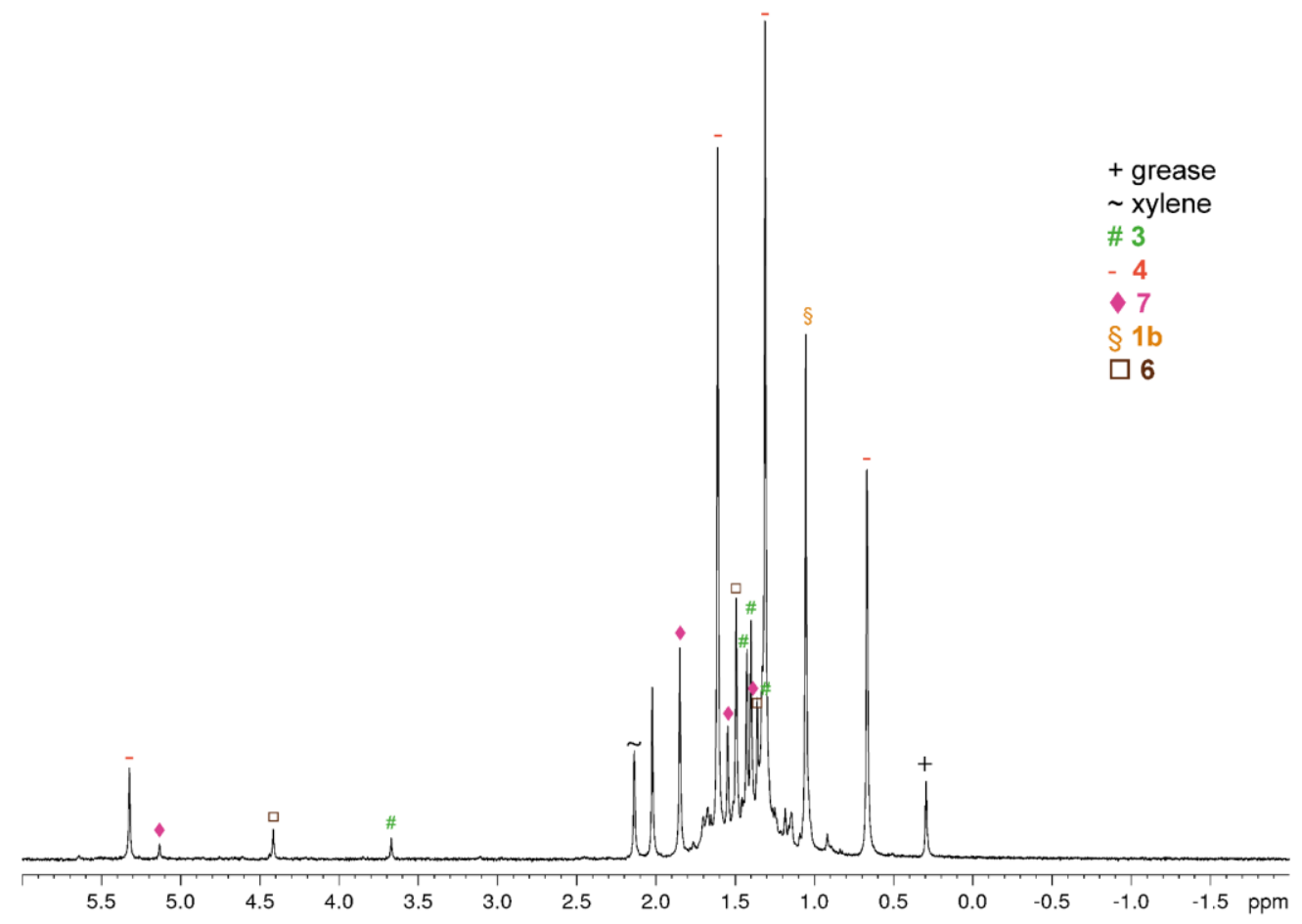

Figure S23: ${ }^{1} \mathrm{H}$ NMR spectrum of the reaction mixture in $\mathrm{C}_{6} \mathrm{D}_{6}$ at room temperature after $1 \mathrm{~h}$.

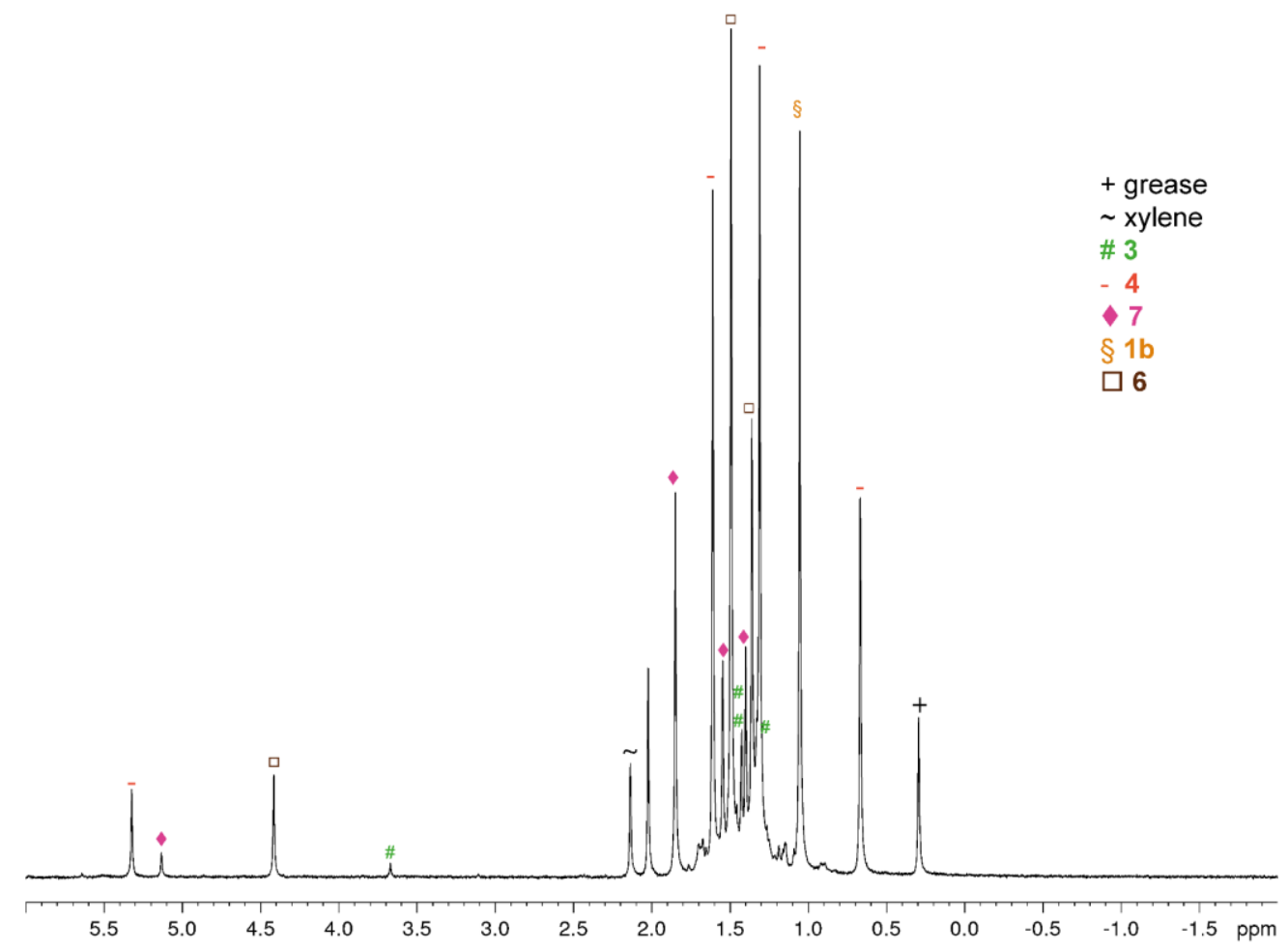

Figure S24: ${ }^{1} \mathrm{H}$ NMR spectrum of the reaction mixture in $\mathrm{C}_{6} \mathrm{D}_{6}$ at room temperature after $4 \mathrm{~h}$. 


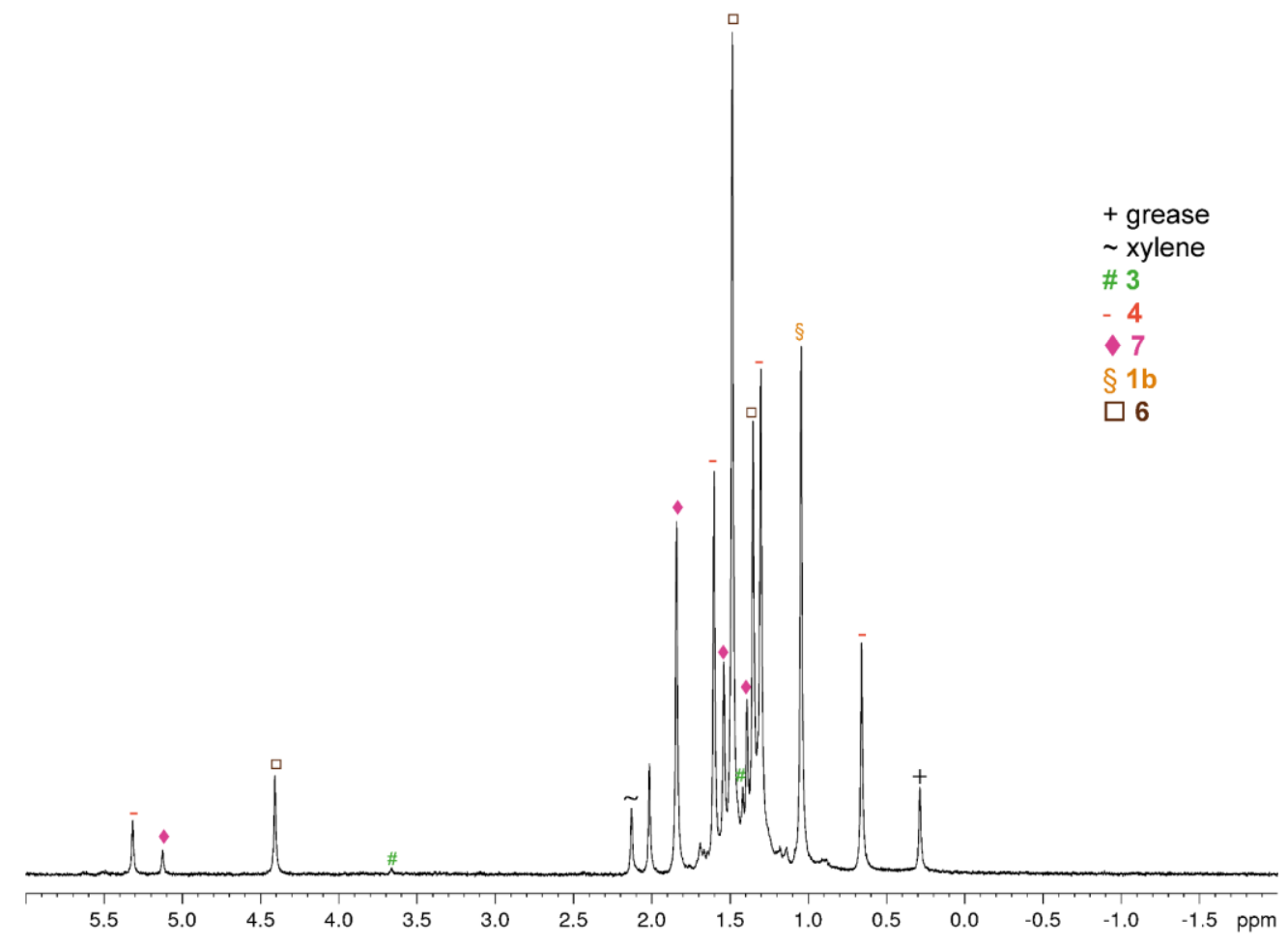

Figure S25: ${ }^{1} \mathrm{H}$ NMR spectrum of the reaction mixture in $\mathrm{C}_{6} \mathrm{D}_{6}$ at room temperature after $7 \mathrm{~h}$.

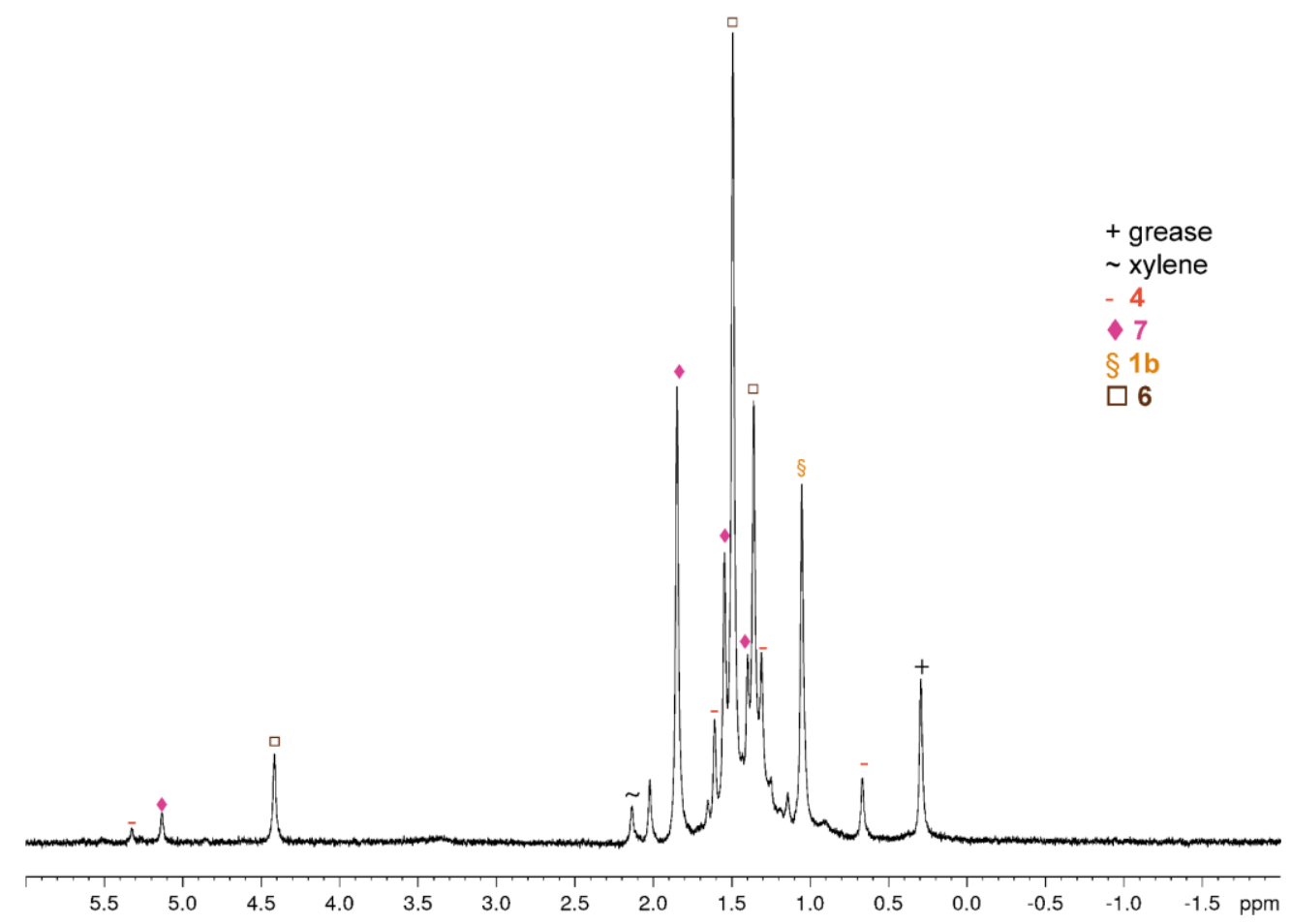

Figure S26: ${ }^{1} \mathrm{H}$ NMR spectrum of the reaction mixture in $\mathrm{C}_{6} \mathrm{D}_{6}$ at room temperature after $25 \mathrm{~h}$. 


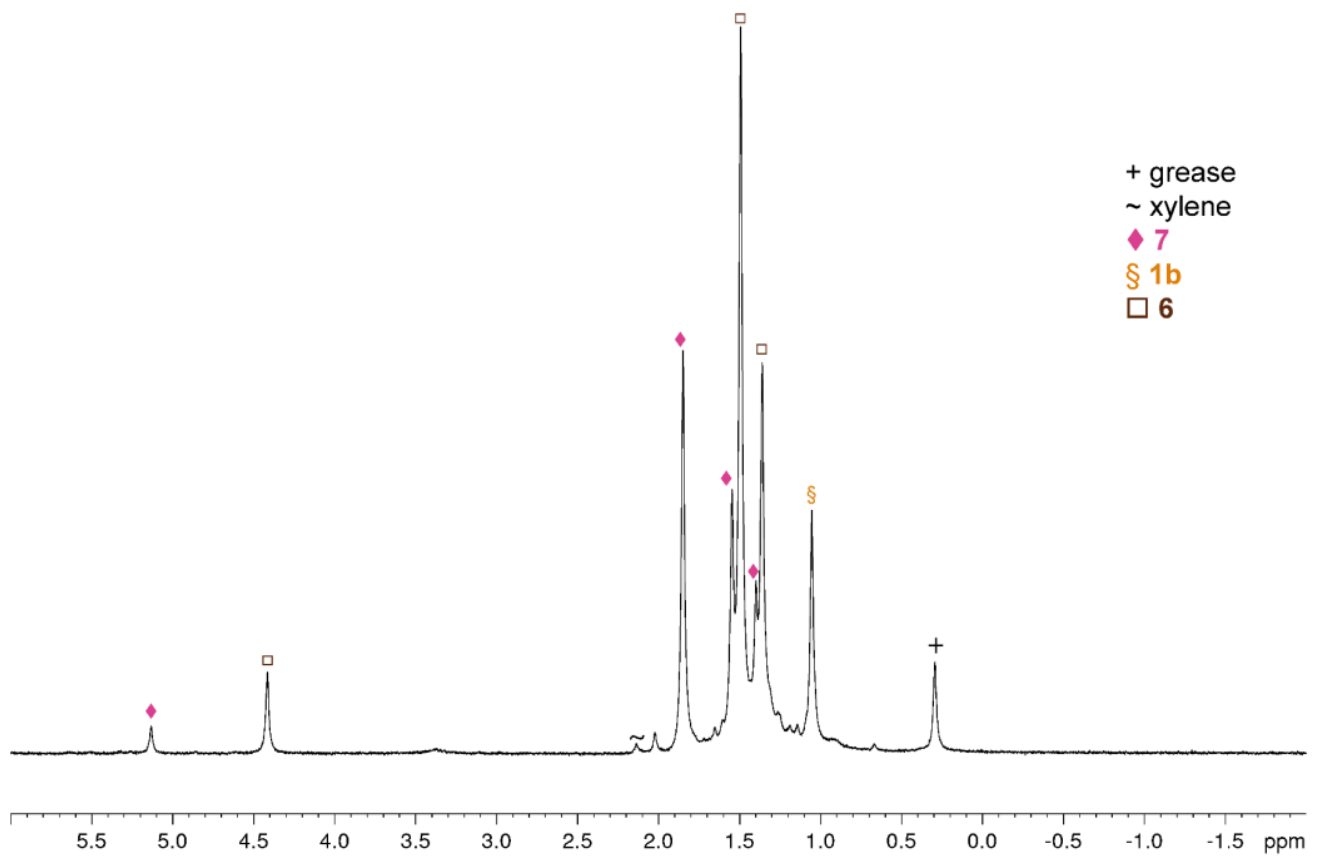

Figure S27: ${ }^{1} \mathrm{H}$ NMR spectrum of the reaction mixture in $\mathrm{C}_{6} \mathrm{D}_{6}$ at room temperature after $45 \mathrm{~h}$.

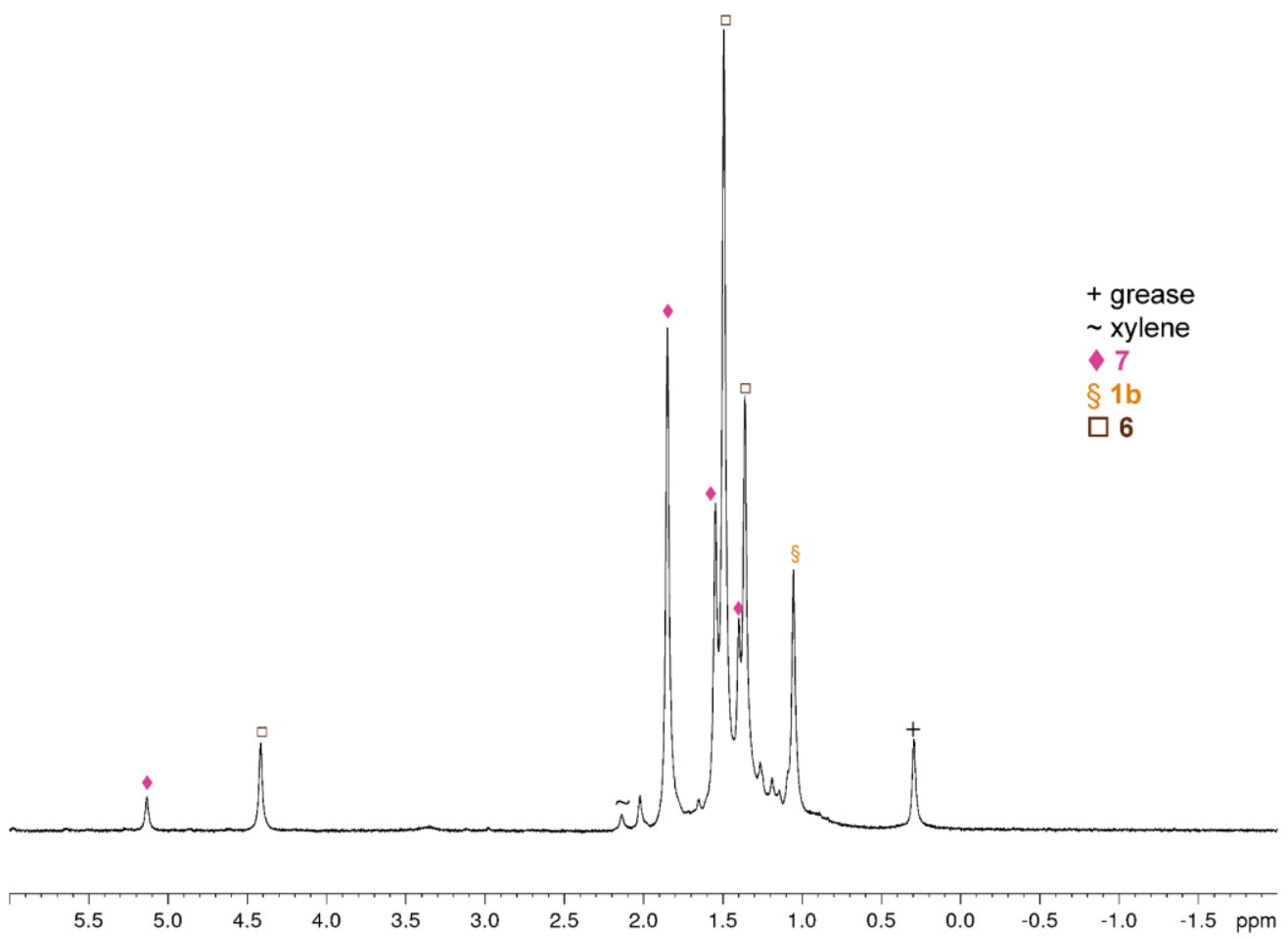

Figure S28: ${ }^{1} \mathrm{H}$ NMR spectrum of the reaction mixture in $\mathrm{C}_{6} \mathrm{D}_{6}$ at room temperature after $69 \mathrm{~h}$. 


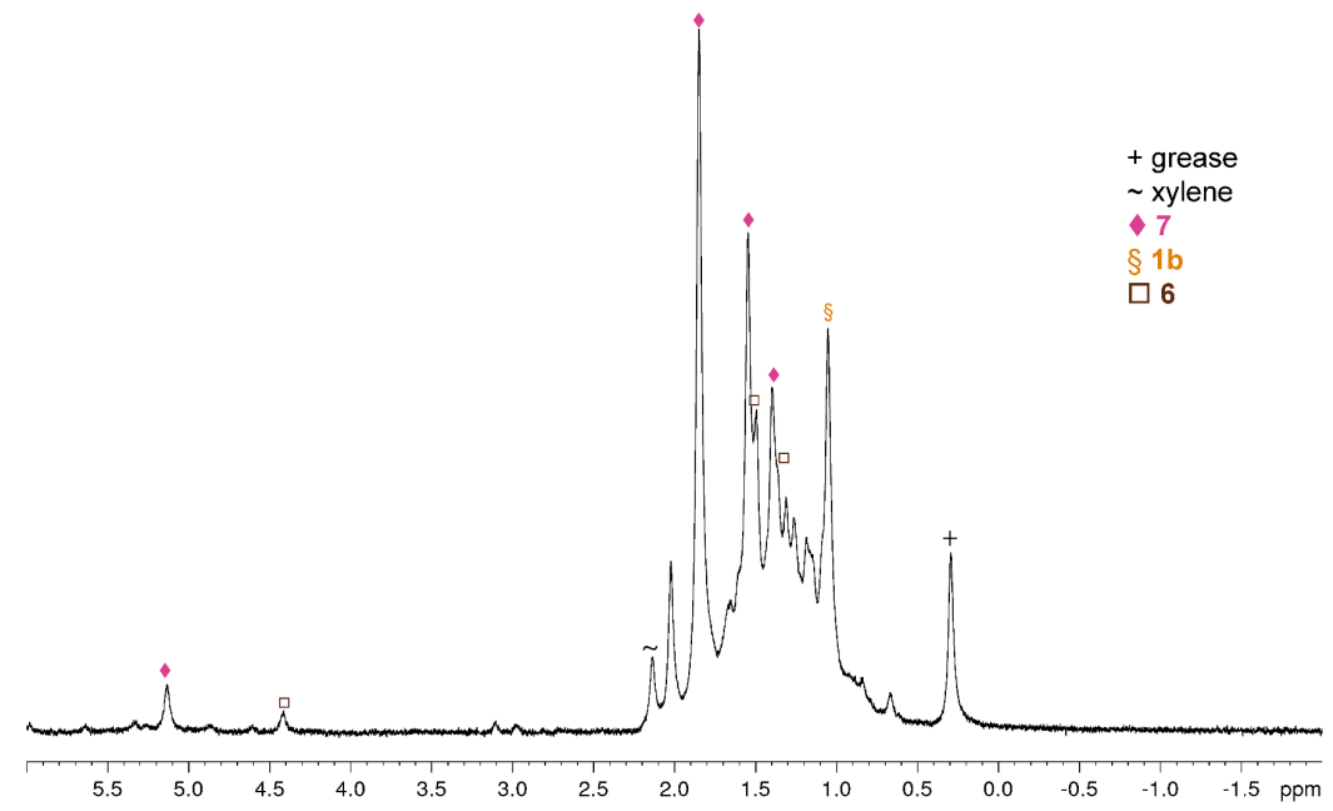

Figure S29: ${ }^{1} \mathrm{H}$ NMR spectrum of the reaction mixture in $\mathrm{C}_{6} \mathrm{D}_{6}$ at room temperature after $93 \mathrm{~h}$. 


\section{EPR spectroscopic investigations}

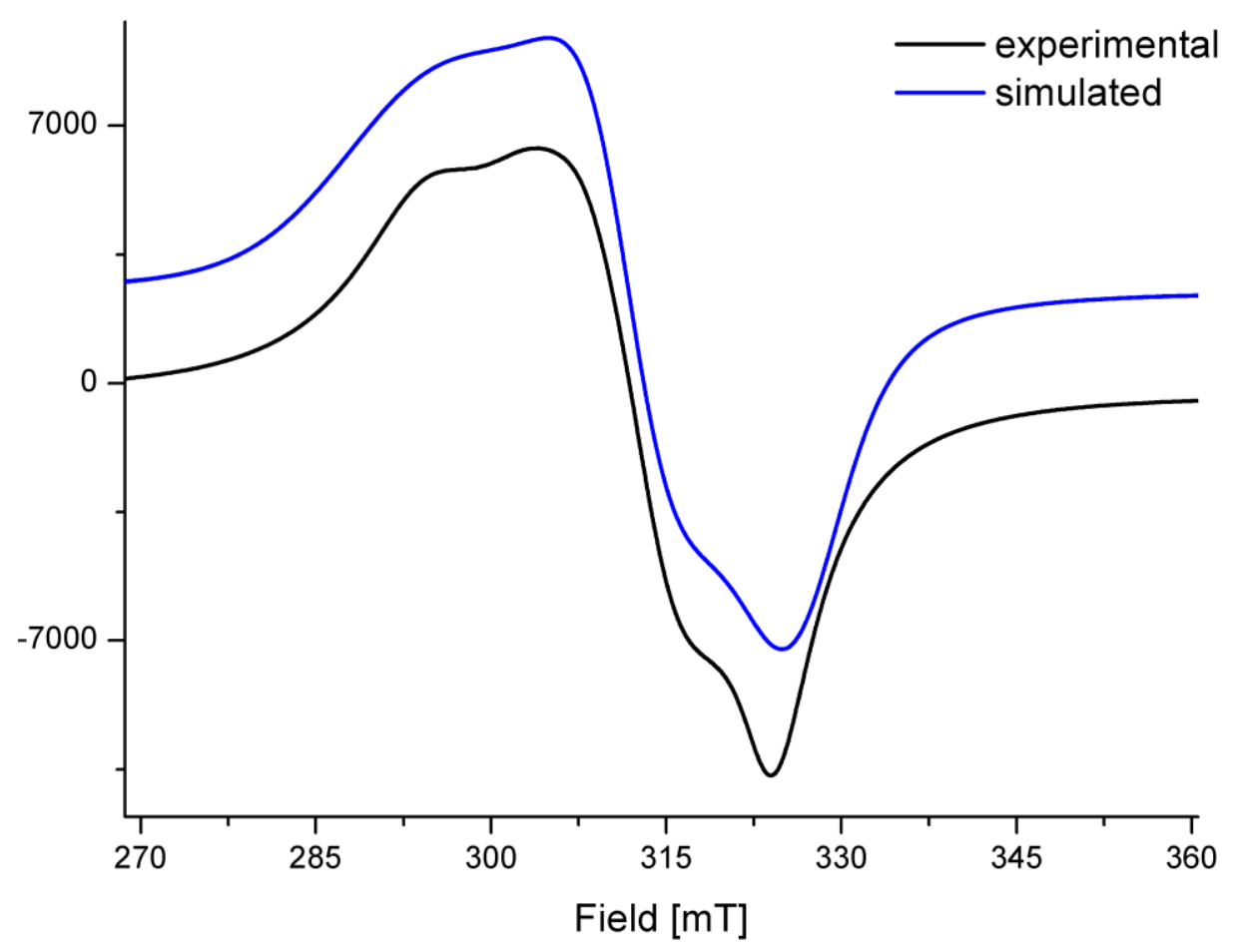

Figure S30: X-band EPR spectrum of 5 (crystalline solid at $77 \mathrm{~K}$ ) experimental (black) and simulated (blue) $g_{x}=2.29632, g_{y}=$ 2.16718, $g_{z}=2.07149, g_{\text {iso }}=2.17833$.

The simulation has been performed using the EasySpin program. ${ }^{[4]}$

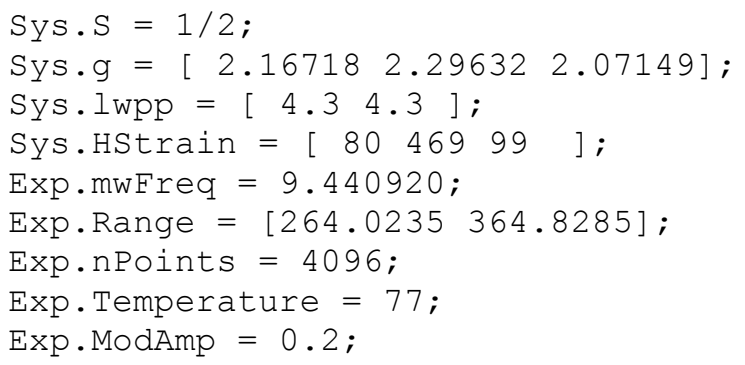




\section{Details on single crystal X-ray structure analysis}

The X-ray diffraction experiments were performed on either an Gemini Ultra diffractometer (Oxford diffraction) with an AtlasS2 detector Mo radiation $(\lambda=0.71073 \AA)(5)$, a GV 50 diffractometer (Rigaku, formerly Agilent Technologies) with TitanS2 detector from applying applying Cu-Ka radiation $(\lambda=1.54178 \AA)(\mathbf{4})$ or Cu-K $\beta$ radiation $(\lambda=1.39222 \AA)(\mathbf{3}, \mathbf{7})$. All measurements were performed at $123 \mathrm{~K}$. For the compounds $(\mathbf{3}, \mathbf{4}, \mathbf{5}, \mathbf{7})$ a numerical absorption correction based on gaussian integration over a multifaceted crystal model and an empirical absorption correction using spherical harmonics as implemented in SCALE3 ABSPACK was applied. All structures were solved by direct methods with ShelXT ${ }^{[7]}$ and Olex ${ }^{[8]}$ and refined by full-matrix least-squares method against $F^{2}$ in anisotropic approximation using ShelXL ${ }^{[7]}$. Hydrogen atoms were refined in calculated positions using riding on pivot atom model.

CCDC-1994413 (3), CCDC-1994415 (4), CCDC-1994414 (5) and CCDC-1994416 (7) contain the supplementary crystallographic data for this paper. These data can be obtained free of charge at www.ccdc.cam.ac.uk/conts/retrieving.html (or from the Cambridge Crystallographic Data Centre, 12 Union Road, Cambridge CB2 1EZ, UK; Fax: + 44-1223-336-033; e-mail: deposit@ccdc.cam.ac.uk). 


\section{$4.1\left[\left(\mathrm{Cp}{ }^{\star} \mathrm{Fe}\right)\left(\mathrm{Cp} \mathrm{p}^{\prime \prime} \mathrm{Co}\right)\left(\mu, \eta^{5}: \eta^{4}-\mathrm{As} 5\right)\right](3)$}

Compound 3 crystallizes from a concentrated solution in $\mathrm{CH}_{2} \mathrm{Cl}_{2}$ layered with acetonitrile at $-30^{\circ} \mathrm{C}$ in the triclinic space group $P \overline{1}$ as dark green blocks. The asymmetric unit contains five molecules $\mathbf{3}$ while four of them are heavily disordered (in one case even four times). Bond lengths and distances are given for the one non-disordered molecule. The structure in solid state is depicted in Figure SX and SX.

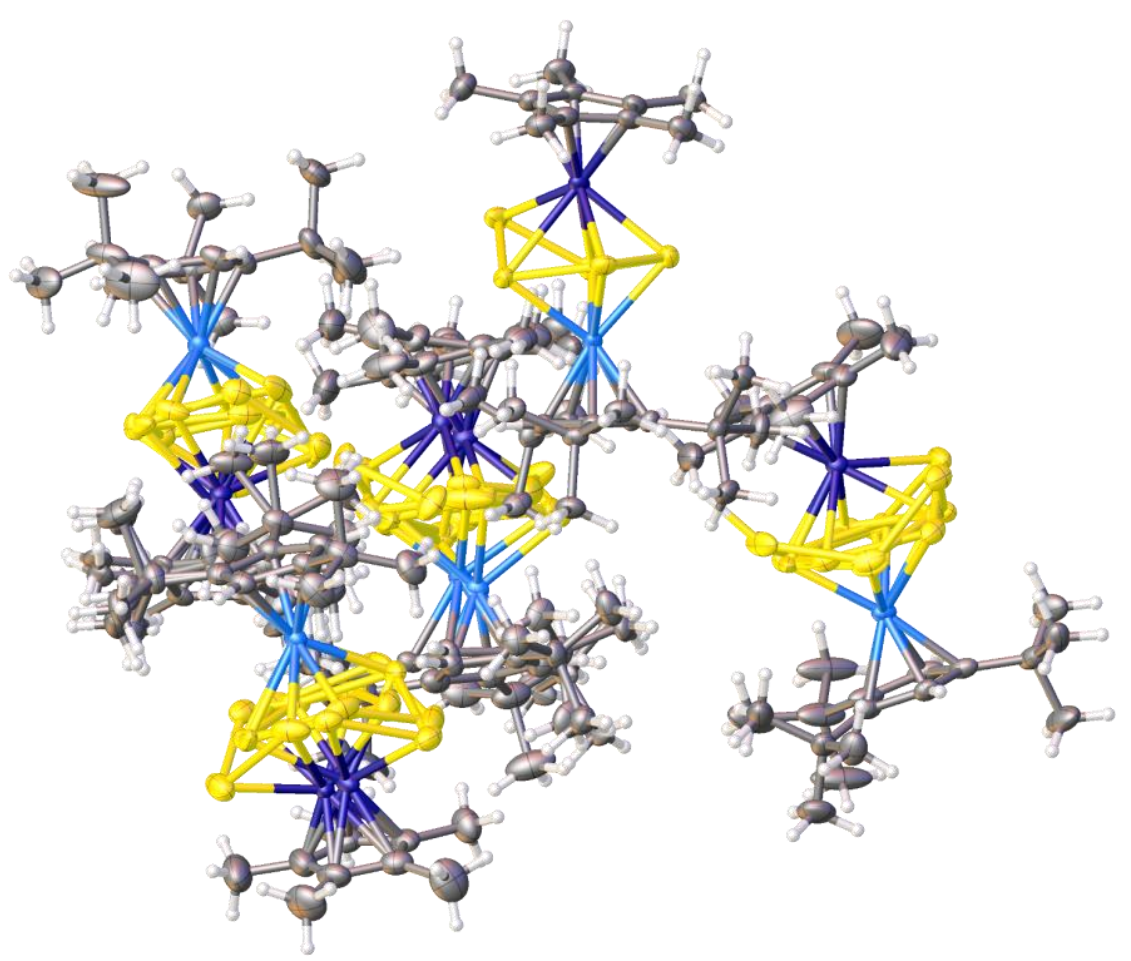

Figure S31: Molecular structure of $\mathbf{3}$ in solid state. Thermal ellipsoids are drawn with $50 \%$ probability level.

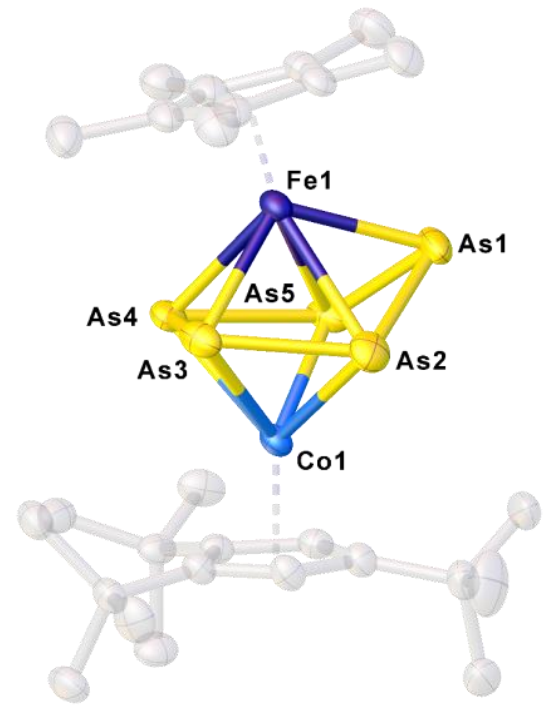

Figure S32: Molecular structure of one independent molecule 3 in solid state. Thermal ellipsoids are drawn with $50 \%$ probability level. Selected bond lengths [Å] and angles [ $\left.{ }^{\circ}\right]$ : Co1-Fe1 3.4241(5), As1-As2 2.3716(6), As2-As3 2.4383(6), As3-As4 2.3401(5), As4-As5 2.4627(5), As1-As5 2.3682(5), Co1-As1 3.6236(5), Co1-As2 2.4259(5), Co1-As3 2.4694(5), Co1-As4 2.4421(6), Co1As5 2.4383(6), Fe1-As1 2.4095(6), Fe1-As2 2.7108(6), Fe1-As3 2.5026(5), Fe1-As4 2.4824(5), Fe1-As5 2.6514(5), As5-As1As2-As3 130.722, Cp*Fe-Cp"'Co 164.996. 


\section{$4.3\left[\left(\mathrm{Cp}{ }^{*} \mathrm{Fe}\right)\left(\mathrm{Cp} p^{\prime \prime} \mathrm{Co}\right)\left(\mu, \eta^{3}: \eta^{3}-\mathrm{As} 3\right)\right](4)$}

Compound 4 crystallizes from a concentrated solution in $\mathrm{CH}_{2} \mathrm{Cl}_{2}$ layered with acetonitrile at $-30^{\circ} \mathrm{C}$ in the monoclinic space group $121 / \mathrm{a}$ as dark green blocks. The asymmetric unit contains one molecule 4. Two 'Bu groups of the Cp"' ligand are disordered over two positions. The structure in solid state is depicted in Figure SX and SX.

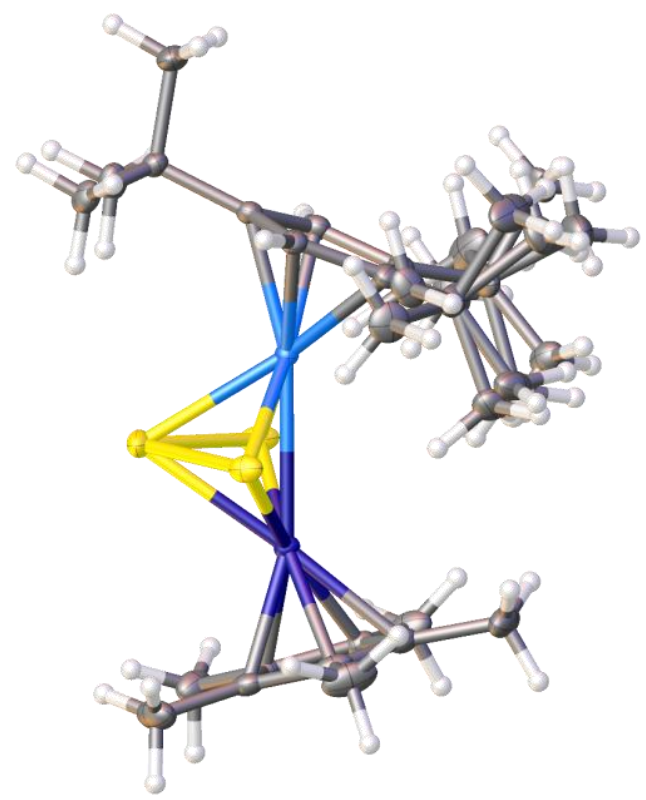

Figure S33: Molecular structure of $\mathbf{4}$ in solid state. Thermal ellipsoids are drawn with $50 \%$ probability level.

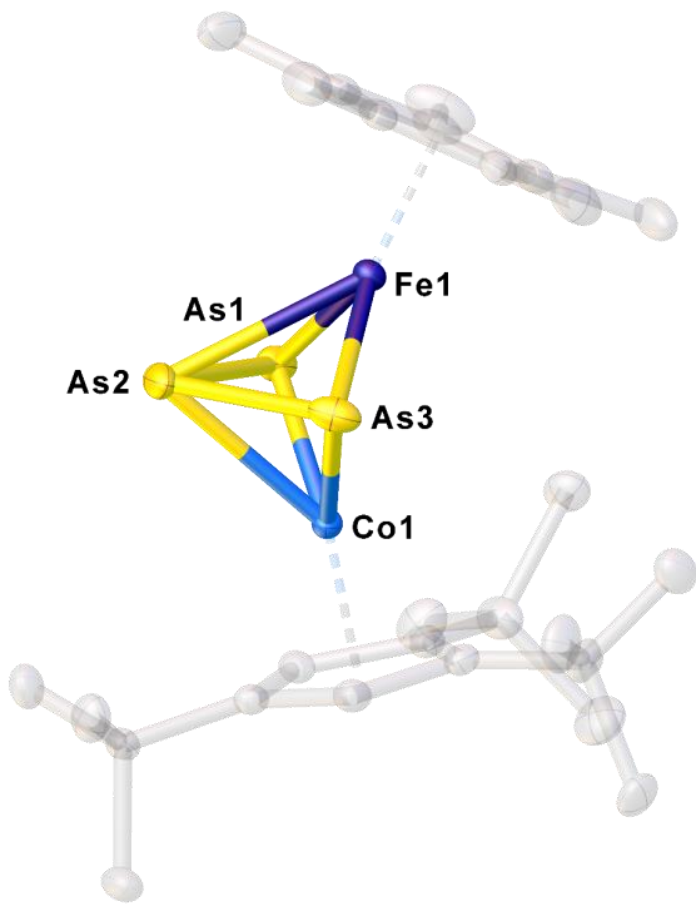

Figure S34: Molecular structure of 4 in solid state. Thermal ellipsoids are drawn with $50 \%$ probability level. Depicted is the part of highest occupation. Selected bond lengths [Å] and angles [०]: As1-As2 2.3933(3), As2-As3 2.3879(3), As1-As3 3.5123(3), Fe1Co1 2.7744(4), Fe1-As1 2.2632(3), Fe1-As2 2.5757(3), Fe1-As3 2.2652(3), Co1-As1 2.3131(3), Co1-As2 2.4739(3), Co1-As3 2.3251(3), Cp*Fe-Cp"'Co 141.827. 


\section{$4.3\left[\left(\mathrm{Cp}{ }^{*} \mathrm{Fe}\right)_{2}\left(\mathrm{Cp}{ }^{\prime \prime} \mathrm{Co}\right)_{2}\left(\mu_{4}, \eta^{4}: \eta^{4}: \eta^{4}: \eta^{3}-\mathrm{As} s_{11}\right)\right](5)$}

Compound $\mathbf{5}$ crystallizes from a concentrated solution in $\mathrm{CH}_{2} \mathrm{Cl}_{2}$ layered with acetonitrile at $-30{ }^{\circ} \mathrm{C}$ in the monoclinic space group $P 2{ }_{1} / C$ as dark brown blocks. The asymmetric unit contains one molecule 5 and 0.85 molecules $\mathrm{CH}_{2} \mathrm{Cl}_{2}$. One $\mathrm{Cp}^{*}$ and one $\mathrm{Cp}^{\prime \prime}$ ligand are disordered over two positions, the $\mathrm{CH}_{2} \mathrm{Cl}_{2}$ molecule is disordered over four positions The structure in solid state is depicted in Figure SX and SX.

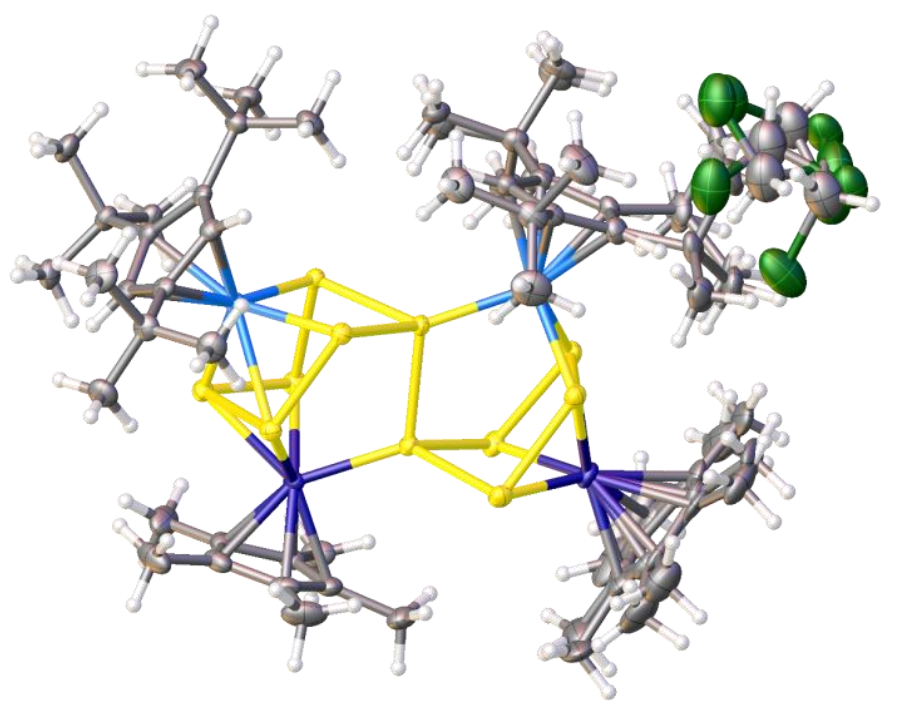

Figure S35: Molecular structure of $\mathbf{5}$ in solid state. Thermal ellipsoids are drawn with $50 \%$ probability level.

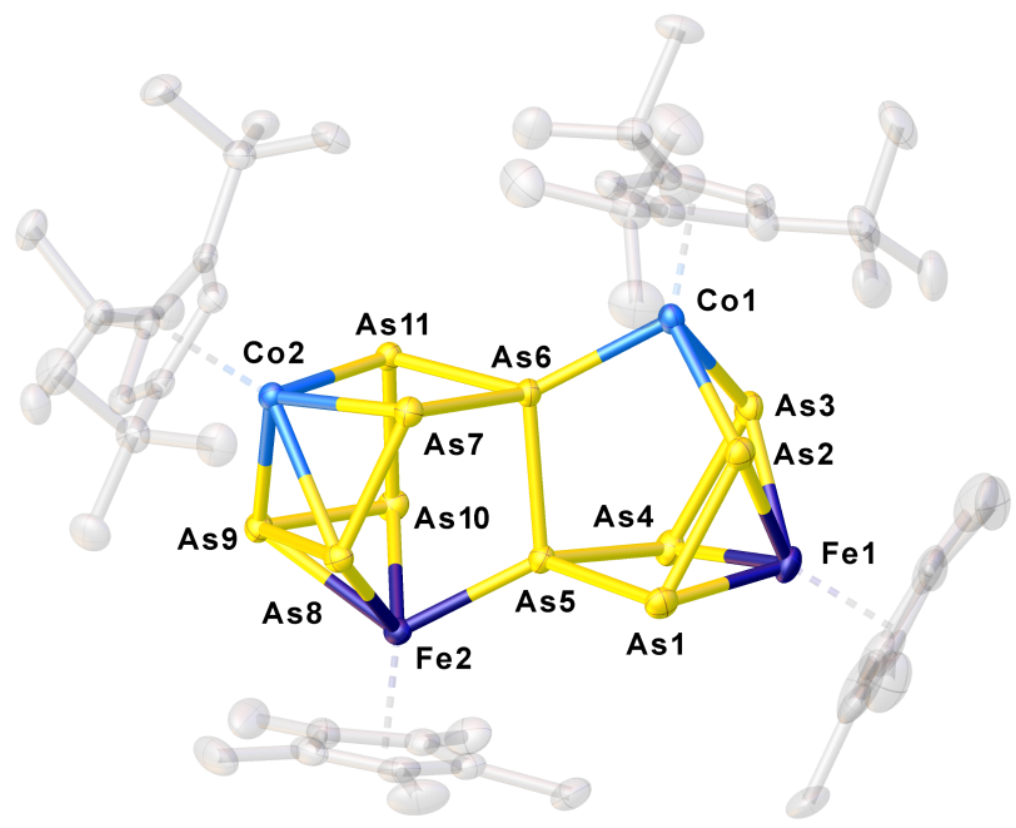

Figure S36: Molecular structure of $\mathbf{5}$ in solid state. Thermal ellipsoids are drawn with $50 \%$ probability level. Depicted is the part of highest occupation. Solvent molecules are omitted for clarity. Selected bond lengths $[\AA \AA]$ and angles [ $\left.{ }^{\circ}\right]$ : As1-As2 2.3812(5), As2-As3 2.7746(5), As3-As4 2.3915(5). As4-As5 2.4316(4), As1-As5 2.4404(5). As5-As6 2.4123(4), As6-As7 2.4208(8), As7-As8 2.3843(4), As8-As9 2.5816(5), As9-As10 2.3812(5), As10-As11 2.4563(4), As6-As11 2.4628(4), Fe1-As1 2.4198(6), Fe1-As2 2.4539(6). Fe1-As3 2.4445(6), Fe1-As4 2.4231(6), Fe2-As5 2.2952(5), Fe2-As8 2.3842(5), Fe2-As9 2.4620(5), Fe2-As10 2.4648(5), Co1-As2 2.35802(5), Co1-As3 2.3646(5), Co1-As6 2.2793(5), Co2-As7 2.4126(5), Co2-As8 2.5740(5), Co2-As9 2.4053(5), Co2-As11 2.4175(5). 


\section{$4.4\left[\left(\mathrm{Cp}{ }^{\star} \mathrm{Fe}\right)_{2}\left(\mathrm{Cp} \mathrm{p}^{\prime \prime} \mathrm{Co}\right)\left(\mu_{3}, \eta^{2}: \eta^{2}: \eta^{2}-\mathrm{As}\right)_{2}\right]$ (7)}

Compound 7 crystallizes from a concentrated solution in toluene layered with acetonitrile at room temperature in the monoclinic space group $C c$ as dark brown blocks. The asymmetric unit contains one molecule 7. The Cp'"Co fragment disordered over two positions. The structure in solid state is depicted in Figure SX and SX.

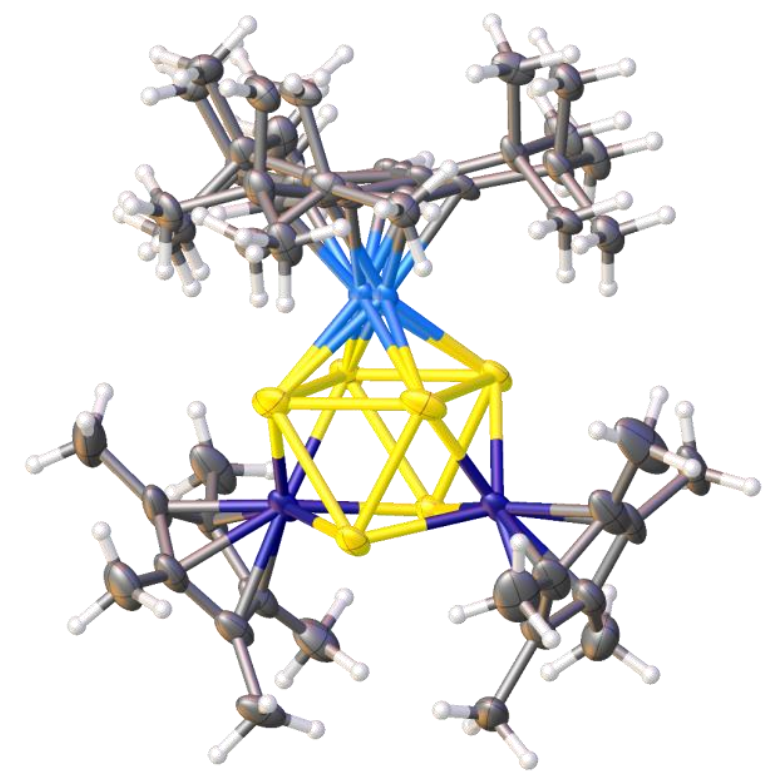

Figure S37: Molecular structure of 7 in solid state. Thermal ellipsoids are drawn with $50 \%$ probability level.

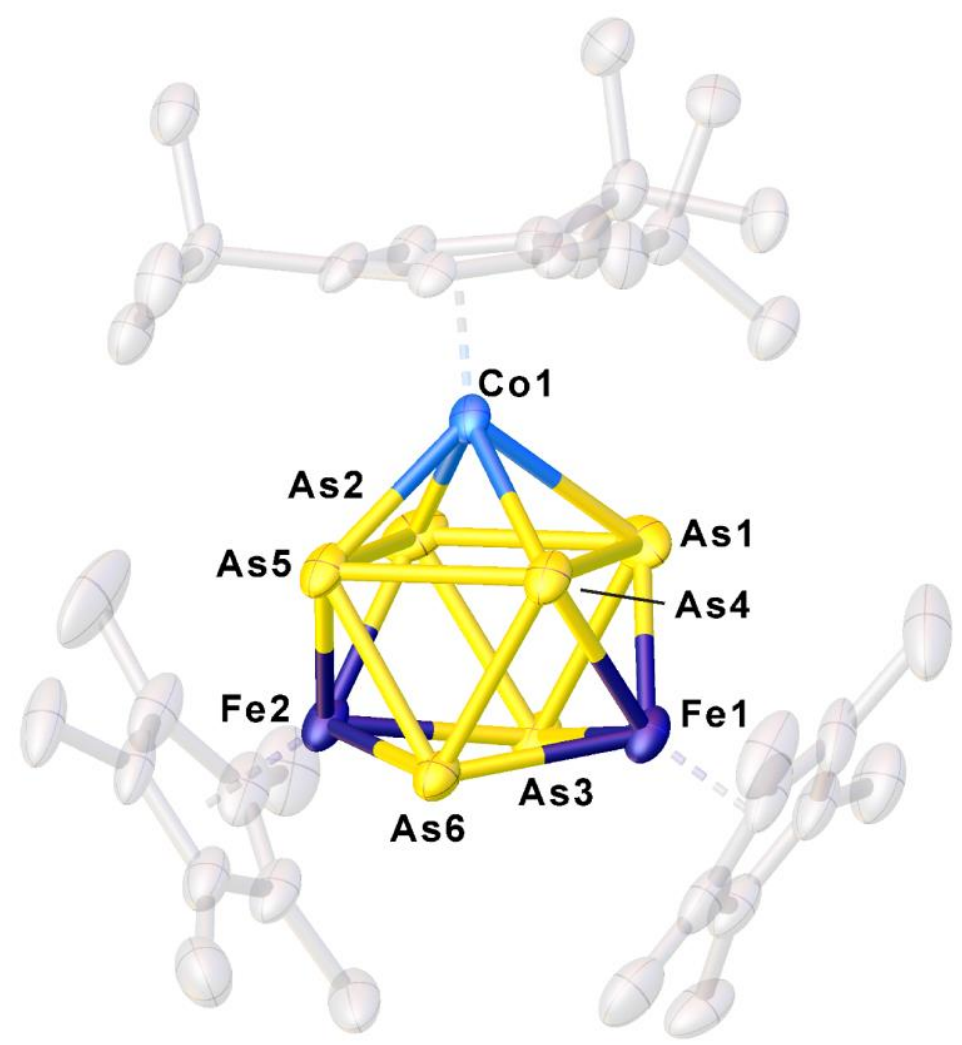

Figure S38: Molecular structure of $\mathbf{7}$ in solid state. Thermal ellipsoids are drawn with $50 \%$ probability level. Depicted is the part of 7 with the highest occupation (70\%). Selected bond lengths [A]] and angles [ [ ]: As1-As2 2.6224(15), As2-As3 2.5446(13), As1As3 2.5285(13), As1-As4 2.7570(12), As2-As5 2.7544(13), As3-As6 2.9347(12), As4-As5 2.5853(11), As5-As6 2.5270(12), As4As6 2.5334(12). 
4.5 Crystallographic information

Table S4: Crystallographic data for all compounds

\begin{tabular}{|c|c|c|c|}
\hline & 3 & 4 & 5 \\
\hline CCDC & 1994413 & 1994415 & 1994414 \\
\hline Formula & $\mathrm{C}_{135} \mathrm{H}_{220} \mathrm{As}_{25} \mathrm{Co}_{5} \mathrm{Fe}_{5}$ & $\mathrm{C}_{27} \mathrm{H}_{44} \mathrm{As}_{3} \mathrm{CoFe}$ & $\begin{array}{c}\mathrm{C}_{54.85} \mathrm{H}_{89.7} \mathrm{As}_{11} \mathrm{Cl}_{1.7} \mathrm{Co} \\
{ }_{2} \mathrm{Fe}_{2}\end{array}$ \\
\hline$D_{\text {calc. }} / \mathrm{g} \mathrm{cm}^{-3}$ & 1.845 & 1.644 & 1.862 \\
\hline$\mu / \mathrm{mm}^{-1}$ & 10.647 & 12.547 & 6.455 \\
\hline Formula Weight & 4290.00 & 708.193 & 1863.11 \\
\hline Colour & clear dark green & clear dark green & clear dark brown \\
\hline Shape & block & block & block \\
\hline Size $/ \mathrm{mm}^{3}$ & $0.14 \times 0.13 \times 0.08$ & $0.35 \times 0.21 \times 0.13$ & $0.62 \times 0.43 \times 0.32$ \\
\hline$T / \mathrm{K}$ & $122.95(16)$ & 296.78(10) & $123(1)$ \\
\hline Crystal System & triclinic & monoclinic & monoclinic \\
\hline Space Group & $P-1$ & $12 / a$ & $P 2_{1} / c$ \\
\hline$a / \AA$ & $12.02431(7)$ & $17.54679(9)$ & $12.8284(2)$ \\
\hline$b / \check{A}$ & $22.74711(14)$ & $9.14890(5)$ & $14.5804(2)$ \\
\hline$c / \AA$ & $29.66301(15)$ & $35.63932(17)$ & $35.7022(6)$ \\
\hline$\alpha /^{\circ}$ & $72.6118(5)$ & 90 & 90 \\
\hline$\beta /^{\circ}$ & $86.0155(5)$ & $90.5219(4)$ & $95.551(2)$ \\
\hline$\gamma /^{\circ}$ & $89.9742(5)$ & 90 & 90 \\
\hline $\mathrm{V} / \AA^{3}$ & $7722.14(8)$ & $5721.08(5)$ & $6646.54(18)$ \\
\hline$Z$ & 2 & 8 & 4 \\
\hline$Z^{\prime}$ & 1 & 1 & 1 \\
\hline Wavelength/Å & 1.39222 & 1.54184 & 0.71073 \\
\hline Radiation type & $\mathrm{Cu} \mathrm{K} \beta$ & $\mathrm{Cu} \mathrm{K}{ }_{\alpha}$ & Mo K ${ }_{a}$ \\
\hline$\theta_{\min } 1^{\circ}$ & 3.520 & 4.96 & 3.364 \\
\hline$\left.\theta_{\max }\right|^{\circ}$ & 73.857 & 67.07 & 32.251 \\
\hline Measured Refl. & 129880 & 56873 & 38659 \\
\hline Independent Refl. & 41988 & 5105 & 20993 \\
\hline $\begin{array}{l}\text { Reflections with I > } \\
2(I)\end{array}$ & 36616 & 5088 & 16754 \\
\hline$R_{\text {int }}$ & 0.0458 & 0.0430 & 0.0232 \\
\hline Parameters & 2427 & 364 & 921 \\
\hline Restraints & 471 & 0 & 552 \\
\hline Largest Peak & 1.322 & 0.4739 & 0.875 \\
\hline Deepest Hole & -0.962 & -0.4008 & -0.700 \\
\hline GooF & 1.072 & 1.0695 & 1.085 \\
\hline$w R_{2}$ (all data) & 0.1087 & 0.0461 & 0.0801 \\
\hline$w R_{2}$ & 0.1040 & 0.0460 & 0.0744 \\
\hline$R_{1}$ (all data) & 0.0510 & 0.0195 & 0.0561 \\
\hline$R_{1}$ & 0.0435 & 0.0194 & 0.0386 \\
\hline
\end{tabular}




\begin{tabular}{|c|c|}
\hline & 7 \\
\hline CCDC & 1994416 \\
\hline Formula & $\mathrm{C}_{37} \mathrm{H}_{59} \mathrm{As}_{6} \mathrm{CoFe}_{2}$ \\
\hline$D_{\text {calc. }} / \mathrm{g} \mathrm{cm}^{-3}$ & 1.877 \\
\hline$\mu / \mathrm{mm}^{-1}$ & 11.146 \\
\hline Formula Weight & 1123.99 \\
\hline Colour & clear dark brown \\
\hline Shape & block \\
\hline Size $/ \mathrm{mm}^{3}$ & $0.31 \times 0.23 \times 0.14$ \\
\hline$T / \mathrm{K}$ & $123(1)$ \\
\hline Crystal System & monoclinic \\
\hline Flack Parameter & $0.035(5)$ \\
\hline Hooft Parameter & $0.051(4)$ \\
\hline Space Group & $C c$ \\
\hline$a / \AA \grave{A}$ & $19.6842(4)$ \\
\hline$b / \AA$ & $15.7329(2)$ \\
\hline$c / \AA$ & $12.8445(2)$ \\
\hline$\alpha /^{\circ}$ & 90 \\
\hline$\beta /^{\circ}$ & $91.174(2)$ \\
\hline$Y I^{\circ}$ & 90 \\
\hline$V / \AA^{3}$ & 3976.97(11) \\
\hline$Z$ & 4 \\
\hline$Z^{\prime}$ & 1 \\
\hline Wavelength/Å & 1.39222 \\
\hline Radiation type & $\mathrm{Cu} \mathrm{K}{ }_{\beta}$ \\
\hline$\theta_{\min } 1^{\circ}$ & 3.247 \\
\hline$\left.\theta_{\max }\right|^{\circ}$ & 74.066 \\
\hline Measured Refl. & 23082 \\
\hline Independent Refl. & 7704 \\
\hline Reflections with I > 2(I) & 7476 \\
\hline$R_{\text {int }}$ & 0.0350 \\
\hline Parameters & 606 \\
\hline Restraints & 128 \\
\hline Largest Peak & 1.441 \\
\hline Deepest Hole & -2.008 \\
\hline GooF & 1.050 \\
\hline$w R_{2}$ (all data) & 0.1117 \\
\hline$w R_{2}$ & 0.1104 \\
\hline$R_{1}$ (all data) & 0.0416 \\
\hline$R_{1}$ & 0.0405 \\
\hline
\end{tabular}




\section{Computational Details}

Gaussian 09 program $^{[9]}$ was used throughout. Density functional theory (DFT) in form of or BP86 $^{[10]}$ (Becke's exchange and Perdew 86 correlation functional) with def2-TZVP all electron basis set was employed. The Natural Bond Orbital (NBO) analysis has been performed with the NBO6 program. ${ }^{[11]}$ The long range dispersion correction GD3BJ was applied. ${ }^{[12]}$ The figures for the supporting information concerning the DFT calculations were created with Chemcraft. ${ }^{[13]}$

Table S5: Total energies for all optimized geometries (BP86/def2-TZVP level of theory).

\begin{tabular}{|c|c|}
\hline & total energy $[\mathrm{Ha}]$ \\
\hline 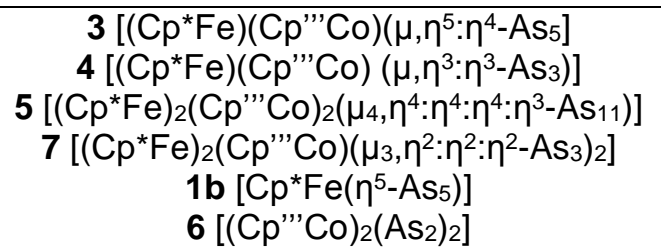 & $\begin{array}{l}-14884.0016082 \\
-10411.5930462 \\
-32004.3018793 \\
-18774.5846073 \\
-12835.2862475 \\
-13042.1875737\end{array}$ \\
\hline
\end{tabular}

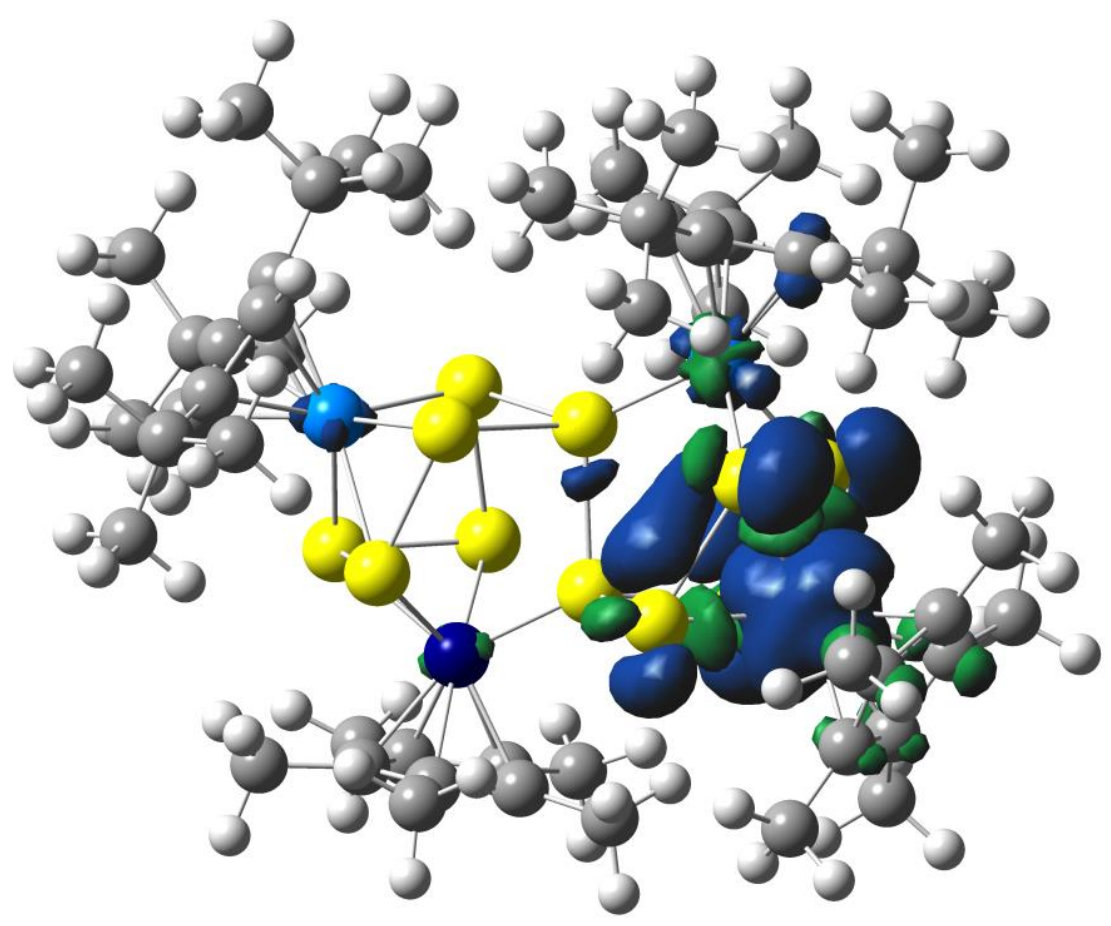

$\begin{array}{llllll}1 & \text { As } & -0,002194 & 52 & \text { C } & -0,000136 \\ 2 & \text { As } & 0,007662 & 53 & \text { C } & 0,000346 \\ 3 & \text { As } & 0,003689 & 57 & \text { C } & 0,013922 \\ 4 & \text { As } & 0,018743 & 58 & \text { C } & -0,000028 \\ 5 & \text { As } & 0,001518 & 62 & \text { C } & -0,000019 \\ 6 & \text { As } & 0,001741 & 66 & \text { C } & 0,000128 \\ 7 & \text { As } & -0,001139 & 67 & \text { C } & 0,000679 \\ 8 & \text { As } & 0,03719 & 68 & \text { C } & -0,00001 \\ 9 & \text { As } & 0,03218 & 72 & \text { C } & -0,000005 \\ 10 & \text { As } & 0,02579 & 76 & \text { C } & -0,013028 \\ 11 & \text { As } & 0,024174 & 77 & \text { C } & 0,000143 \\ 12 & \text { Co } & 0,007323 & 81 & \text { C } & 0,000096 \\ 13 & \text { Co } & -0,011191 & 85 & \text { C } & -0,000031 \\ 14 & \text { Fe } & -0,007745 & 89 & \text { C } & -0,014973 \\ 15 & \text { Fe } & 0,898029 & 90 & \text { C } & 0,000174 \\ 16 & \text { C } & -0,000179 & 94 & \text { C } & -0,016562 \\ 17 & \text { C } & 0,000363 & 95 & \text { C } & 0,000006 \\ 19 & \text { C } & -0,00053 & 99 & \text { C } & 0,002493 \\ 20 & \text { C } & 0,000038 & 103 & \text { C } & -0,000252 \\ 22 & \text { C } & -0,000323 & 107 & \text { C } & -0,011837 \\ 23 & \text { C } & -0,000185 & 108 & \text { C } & -0,001009 \\ 24 & \text { C } & 0,000453 & 112 & \text { C } & -0,009888 \\ 25 & \text { C } & -0,000873 & 113 & \text { C } & -0,000365 \\ 26 & \text { C } & 0,000169 & 117 & \text { C } & -0,000152 \\ 27 & \text { C } & -0,004621 & 121 & \text { C } & -0,000772 \\ 28 & \text { C } & 0,0001 & 122 & \text { C } & -0,001133 \\ 32 & \text { C } & 0,005812 & 126 & \text { C } & 0,001244 \\ 34 & \text { C } & 0,000677 & 130 & \text { C } & 0,004344 \\ 35 & \text { C } & 0,000091 & 134 & \text { C } & 0,001547 \\ 39 & \text { C } & -0,000518 & 138 & \text { C } & 0,001928 \\ 40 & \text { C } & -0,00259 & 142 & \text { C } & 0,002985 \\ 42 & \text { C } & -0,000685 & 146 & \text { C } & 0,002714 \\ 43 & \text { C } & 0,000051 & 150 & \text { C } & 0,001647 \\ 47 & \text { C } & -0,000025 & 154 & \text { C } & 0,002793 \\ 51 & \text { C } & 0,000013 & & & \end{array}$

Figure S39. Isosurface of the spin density in $\mathbf{5}$ and spin densities with hydrogens summed into heavy atoms. 


\section{References}

[1] J. J. Schneider, D. Wolf, C. Janiak, O. Heinemann, J. Rust, C. Krüger, Chem. Eur. J. 1998, 4, 1982.

[2] O. J. Scherer, C. Blath, G. Wolmershäuser, J. Organomet. Chem. 1990, 387, C21-C24.

[3] F. Baumann, E. Dormann, Y. Ehleiter, W. Kaim, J. Kärcher, M. Kelemen, R. Krammer, D. Saurenz, D. Stalke, C. Wachter et al., J. Organomet. Chem. 1999, 587, 267.

[4] S. Stoll, A. Schweiger, J. Magn. Reson. 2006, 178, 42.

[5] R. C. Clark, J. S. Reid, Acta Cryst. 1995, A51, 887.

[6] CrysAlisPro Software system, Agilent Technologies UK Ltd, Yarnton, Oxford, UK (2014).

[7] G. M. Sheldrick, Acta Cryst. 2015, C71, 3.

[8] O. V. Dolomanov, I. J. Bourhis, R. J. Gildea, Howard, J. A. K., H. Puschmann, J. Appl. Cryst. 2009, 42, 339.

[9] M. J. Frisch, G. W. Trucks, H. B. Schlegel, G. E. Scuseria, M. A. Robb, J. R. Cheeseman, G. Scalmani, V. Barone, B. Mennucci, G. A. Petersson, H. Nakatsuji, M. Caricato, X. Li, H. P. Hratchian, A. F. Izmaylov, J. Bloino, G. Zheng, J. L. Sonnenberg, M. Hada, M. Ehara, K. Toyota, R. Fukuda, J. Hasegawa, M. Ishida, T. Nakajima, Y. Honda, O. Kitao, H. Nakai, T. Vreven, J. A. Montgomery, Jr., J. E. Peralta, F. Ogliaro, M. Bearpark, J. J. Heyd, E. Brothers, K. N. Kudin, V. N. Staroverov, T. Keith, R. Kobayashi, J. Normand, K. Raghavachari, A. Rendell, J. C. Burant, S. S. Iyengar, J. Tomasi, M. Cossi, N. Rega, J. M. Millam, M. Klene, J. E. Knox, J. B. Cross, V. Bakken, C. Adamo, J. Jaramillo, R. Gomperts, R. E. Stratmann, O. Yazyev, A. J. Austin, R. Cammi, C. Pomelli, J. W. Ochterski, R. L. Martin, K. Morokuma, V. G. Zakrzewski, G. A. Voth, P. Salvador, J. J. Dannenberg, S. Dapprich, A. D. Daniels, O. Farkas, J. B. Foresman, J. V. Ortiz, J. Cioslowski, and D. J. Fox, Gaussian, Inc., Wallingford CT, 2013.

[10]a) J. P. Perdew, Phys. Rev. B, 1986, 8822; b) A. D. Becke, Phys. Rev. A, 1988, 3098.

[11]NBO 6.0. E. D. Glendening, J. K. Badenhoop, A. E. Reed, J. E. Carpenter, J. A. Bohmann, C. M. Morales, C. R. Landis, and F. Weinhold (Theoretical Chemistry Institute, University of Wisconsin, Madison, WI, 2013), http://nbo6.chem.wisc.edu.

[12] a) S. Grimme, J. Antony, S. Ehrlich, H. Krieg, J. Chem. Phys. 2010, 132, 154104; b) S. Grimme, S. Ehrlich, L. Goerigk, J. Comp. Chem. 2011, 32, 1456.

[13] Chemcraft - graphical software for visualization of quantum chemistry computations. https://www.chemcraftprog.com. 